\title{
Experimental and Numerical Study on Modal Dynamic Response of Water-Surrounded Slender Bridge Pier with Pile Foundation
}

\author{
Yulin Deng, ${ }^{1}$ Qingkang Guo, ${ }^{1}$ and Lueqin $\mathrm{Xu}^{2}$ \\ ${ }^{1}$ Department of Road and Bridge Engineering, Wuhan University of Technology, Wuhan 430063, China \\ ${ }^{2}$ Department of Civil Engineering, Chongqing Jiaotong University, Chongqing 400074, China \\ Correspondence should be addressed to Yulin Deng; dengyulin@whut.edu.cn
}

Received 18 January 2017; Revised 28 February 2017; Accepted 2 March 2017; Published 2 May 2017

Academic Editor: Mickaël Lallart

Copyright (c) 2017 Yulin Deng et al. This is an open access article distributed under the Creative Commons Attribution License, which permits unrestricted use, distribution, and reproduction in any medium, provided the original work is properly cited.

\begin{abstract}
This paper presents an experimental program performed to study the effect of fluid-structure interaction on the modal dynamic response of water-surrounded slender bridge pier with pile foundation. A reduced scale slender bridge pier specimen is built and tested through forced vibration method. The vibration periods of the first four lateral modes, including the first two modes along $x$ axis and the first two modes along $y$-axis, are measured based on the specimen submerged by 16 levels of water and designated with 4 levels of tip mass. Three-dimensional (3D) finite-element models are established for the tested water-pier system and analyzed under various combined cases of water level and tip mass. Percentage increases of vibration periods with respect to dry vibration periods (i.e., vibration periods of the specimen without water) are determined as a function of water level and tip mass to evaluate the effect of fluid-structure interaction. The numerical results are successfully validated against the recorded test data. Based on the validated models, the modal hydrodynamic pressures are calculated to characterize the 3D distribution of hydrodynamic loads on the pier systems. The research provides a better illumination into the effect of fluid-structure interaction on the modal dynamic response of deepwater bridges.
\end{abstract}

\section{Introduction}

Bridges with high and slender piers have widely been found in deepwater areas like estuaries, straits, reservoirs, and so on. In general, the piers, such as those of Miaoziping Bridge $[1,2]$, Sutong Bridge [3, 4], and China East Sea Bridge [5], are composed of a group of piles connected by a large pile cap and a high reinforced concrete column (or bent) which is submerged partially in water. The dynamics of such bridge piers require special considerations which do not arise for piers elevating on land. It is well known that when a structure vibrates in water due to various dynamic loads such as seismic excitations, it stimulates acceleration in the water inducing an extra force on the structure. And hence, during evaluation of the dynamic response of deepwater bridges with slender piers under earthquakes, one of the key factors which should be taken into account is the fluid-structure interaction between the vibrating bridge pier and the surrounding water. Previous researches have been directed toward examining the effect of fluid-structure interaction on deepwater structures, such as towers, dams, offshore platforms, and wind farms. The research efforts have confirmed that fluid-structure interaction might cause considerable change to the dynamic characteristics of the deepwater structures, producing additional hydrodynamic loads [6-9].

In order to provide a better understanding of fluidstructure interaction problems, several analytical approaches have been proposed concerning cylindrical structures, such as piles or towers, standing in water [10-12]. These research attempts can be typically classified into three categories, that is, (i) added mass formulations in which the effect of fluidstructure interaction is approximated by added mass designated to the structure [13-16], (ii) continuum based solutions in which the wave equation involving hydrodynamic pressure is applied [17-19], and (iii) numerical simulations in which either finite or boundary elements are utilized to discretize the surrounding water $[9,20-24]$. Along with the development of analytical and numerical methods, the application of 
experimental approach has provided quite a few supportive test data for the theoretical research efforts [25-27]. Goto and Toki [25] conducted a dynamic experiment on cantilevered pier specimens submerged in water and verified the frequency-domain equation based on radiation wave theory used to compute the hydrodynamic pressure loads on piers during earthquakes. Pegg [26] carried out modal tests on submerged cylinders to obtain a series of curves relating the added hydrodynamic mass and damping to the vibration frequency of the structure. Maheri and Severn [27] designed a series of vibration tests on cantilevered columns surrounded by water and proved that the classical added mass theory can only be applied to single-degree-of-freedom systems. Wu and Hsieh [28] proposed a simple experimental method to determine the frequency-dependent added mass and added mass moment of inertia for a floating body in heave and pitch motions. It can be found that earlier experimental researches were largely directed to supporting particular theoretical solutions based on a single cantilevered column or a circular cylinder which might be simplistic for a bridge substructure.

In a recent study, Wei et al. [24] carried out an experimental program to investigate the modal dynamic response of bridge pile foundations submerged in water. In this study, the piles, the pile cap, and the pier were all incorporated into one specimen that should be more typical of a real bridge substructure, but the research interest was led to the dynamic modal response of the pile foundations due to fluid-structure interaction and the pier was totally above the water surface. As lots of deepwater bridges are surrounded by water up to the piers and some bridges, such as Miaoziping Bridge $[1,2]$, cross reservoirs with most part of the piers submerged in water, the previous research findings focusing on single cantilevered columns may be inappropriate to be employed directly in understanding the modal dynamic behavior of a slender bridge pier surrounded by water, especially when the pier is submerged partially and the pile foundation with a cap is totally immersed in water.

In this work, an experimental program was designed to investigate the influence of fluid-structure interaction on modal dynamic response of water-surrounded slender bridge pier supported by pile foundation. The test specimen was built based on a reduced scale model which was inspired by a prototype bridge in China, and the effects of surrounding water levels and tip mass weights were examined in the tests. Three-dimension (3D) numerical simulations were performed to obtain the modal dynamic response and modal hydrodynamic pressure of the slender pier specimen corresponding to different water levels and tip masses. The numerical results were then validated against test data and the findings involving fluid-structure interaction were discussed.

\section{Experimental Program}

2.1. Test Setup. As shown in Figure 1, a steel tank was designed and built specially to provide a water environment for the test specimen. The slender bridge pier specimen was fixed at the bottom of the tank which was then filled with water to specified levels. The dimensions of the water tank were chosen based on preliminary numerical simulations in which

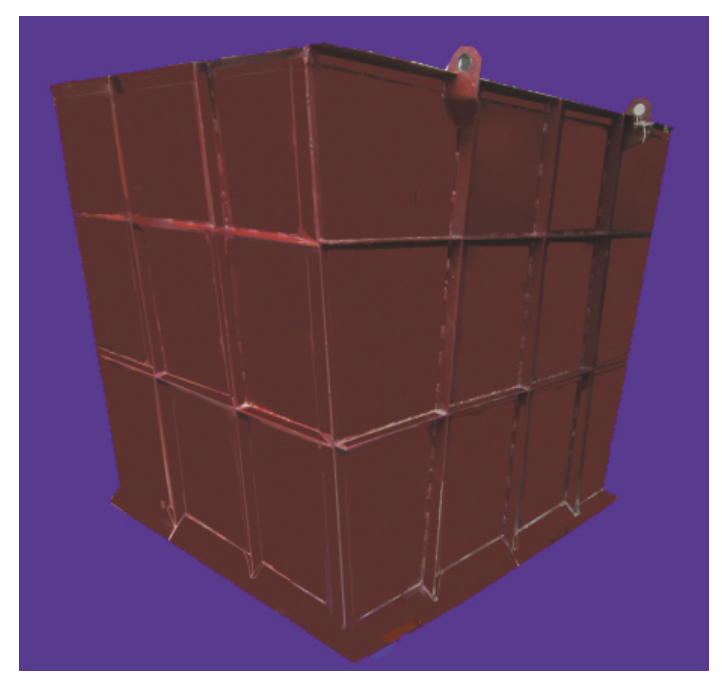

FIGURE 1: Overview of the steel water tank designed for the dynamic tests.

energy dissipation characteristics of propagating waves for different dimensions were identified through reduction of wave reflection at the tank's walls, as presented in detail later in this paper. The selected dimensions of the tank are believed to have little effect on the test results.

As shown in Figure 2, the steel tank is $1.8 \mathrm{~m}$ deep, $1.8 \mathrm{~m}$ long at the bottom side and $2.4 \mathrm{~m}$ long at the top side, and $1.4 \mathrm{~m}$ wide. The steel water tank was constructed of four $6 \mathrm{~mm}$ thick lateral plates and one $22 \mathrm{~mm}$ thick bottom plate. All the steel plates were reinforced with sufficient stiffening ribs to avoid local buckling. The tank was fixed on a sturdy concrete foundation. A $50 \mathrm{~mm}$ thick steel plate was welded to the bottom plate in the center, as illustrated in Figure 2, in order to fix the test specimens. A water outlet valve was installed at the bottom of one of the lateral plates, through which a full-filled tank could be emptied in 30 minutes. Water supply through a water pipe was also installed to control water level in the tank. All the steel plates used for the tank have a density of $7,850 \mathrm{~kg} / \mathrm{m}^{3}$ and Young's modulus of $206 \mathrm{GPa}$.

2.2. Test Specimens. The slender bridge pier specimen tested in this work was constructed based on a reduced scale model corresponding to a prototype deepwater bridge as shown in Figure 3. The original slender pier is seated on a pile cap supported by six reinforced concrete piles. The total height of the pier is $50 \mathrm{~m}$ and the cross-section is $9 \times 4 \mathrm{~m}$. The piles are $40 \mathrm{~m}$ long with a segment of $4.5 \mathrm{~m}$ above the scour line. The pier was constructed using Chinese Grade C40 concrete (Ministry of Communications of China 2004), with Young's modulus of $31.5 \mathrm{GPa}$, and the piles and cap were constructed using C30 concrete (Ministry of Communications of China 2004), with Young's modulus of $30 \mathrm{GPa}$.

Based on a reduced scale, the slender pier specimen was built, consisting of six steel tube piles, a concrete-filled steel cap, and a reinforced concrete pier body, as shown in Figure 4. Steel tubes, $0.05 \mathrm{~m}$ in diameter and $2.5 \mathrm{~mm}$ in thick, were used to model the reinforced concrete piles mainly for ease 

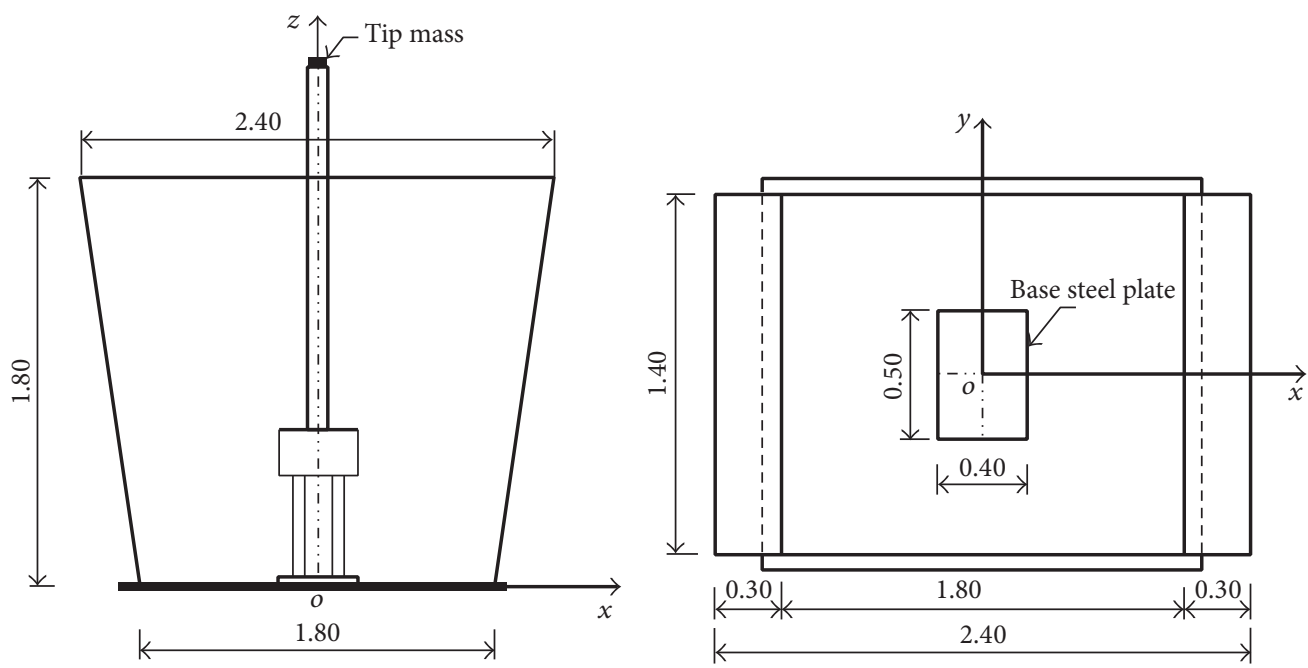

FIGURE 2: Dimensions of the steel water tank; all dimensions are in meters.
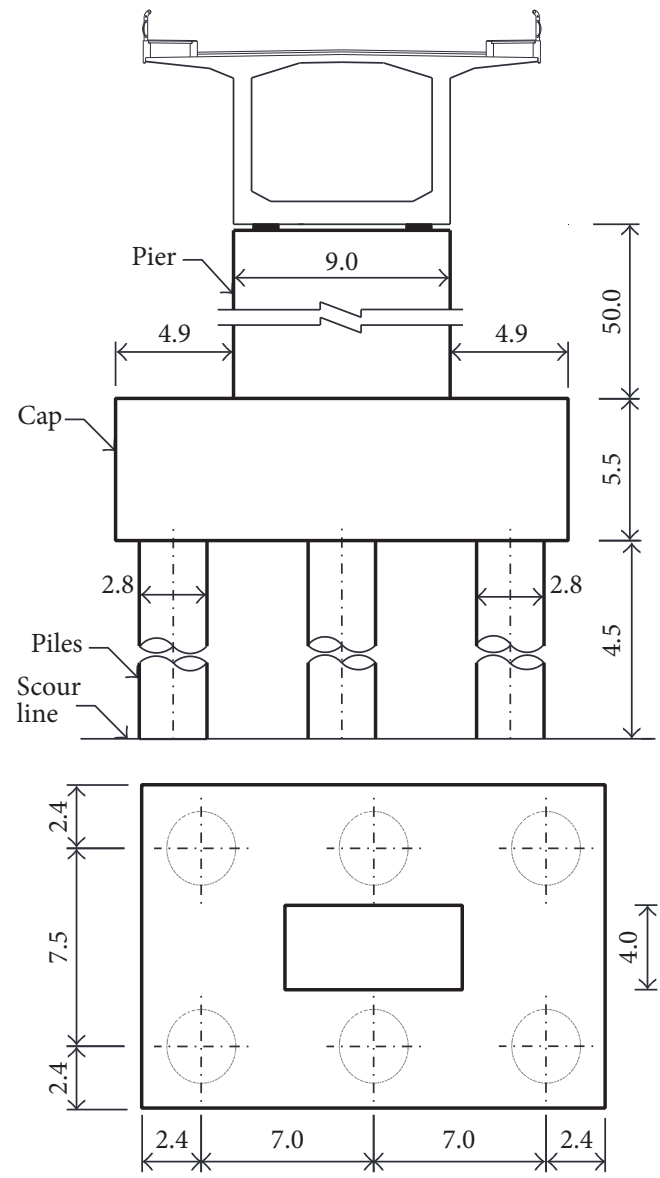

FIGURE 3: Dimensions of the prototype slender bridge pier; all dimensions are in meters.

of manufacture and safety of loading. The tubes were welded at one end to the aforementioned $5 \mathrm{~mm}$ thick steel plate fixed on the tank's bottom plate and others were welded to the pile cap. The pile cap was built using a concrete-filled steel box in order to yield a secure pile-to-cap connection. The pile cap is $0.60 \times 0.40 \times 0.20 \mathrm{~m}$ in dimensions and consists of two $0.60 \times 0.20 \times 0.005 \mathrm{~m}$ lateral steel plates in the long side, two $0.40 \times 0.20 \times 0.005 \mathrm{~m}$ lateral steel plates in the short side and a $0.60 \times 0.40 \times 0.01 \mathrm{~m}$ steel base plate, and inner cast-in-situ concrete. All the steel plates of the cap have a density of $7,850 \mathrm{~kg} / \mathrm{m}^{3}$ and Young's modulus of $210 \mathrm{GPa}$. The pier was made of $\mathrm{C} 15$ concrete according to Chinese code (Ministry of Communications of China 2015), with a density of $2,300 \mathrm{~kg} / \mathrm{m}^{3}$ and Young's modulus of $22 \mathrm{GPa}$. The slender pier is $1.6 \mathrm{~m}$ high with a cross-section of $0.30 \times$ $0.10 \mathrm{~m}$. It is reinforced with eight Chinese Grade HRB400 (Ministry of Communications of China 2015) longitudinal steel bars with a diameter of $10 \mathrm{~mm}$ and HPB300 (Ministry of Communications of China 2015) stirrups with a diameter of $6 \mathrm{~mm}$ placed at a vertical spacing of $0.1 \mathrm{~m}$.

During a test, a steel brick was installed at the top of the pier to stimulate the mass of superstructure. In order to examine the effect of bridge superstructure mass, three steel bricks, weighting $12.1,23.4$, and $31.7 \mathrm{~kg}$, respectively, were prepared in advance for the tests.

2.3. Measurements and Test Procedure. In this test, forced vibration method was applied to identify the dynamic properties of the pier specimen. A special hammer with a stick handle of $1.8 \mathrm{~m}$ long was used to excite the specimen from outside the tank so that the vibration of the water tank could be avoided. Since the impact hammer could not be reasonably waterproofed, the impact zone was selected to be located near the top of the pier above the maximum water level. Forced vibration tests were conducted repeatedly for different water levels and tip masses. Modal dynamic response of the specimen was monitored using eight CA-YD-103 accelerometers with a frequency range of $0.5 \mathrm{~Hz}-12 \mathrm{kHz}$, as shown in Figure 5. All the accelerometers were protected with reliable waterproof measures to enable accurate signal transfer. Data acquisition was carried out through the uTekl7900 system provided by the China Wuhan uTekl Electronic Limited Liability Company. 


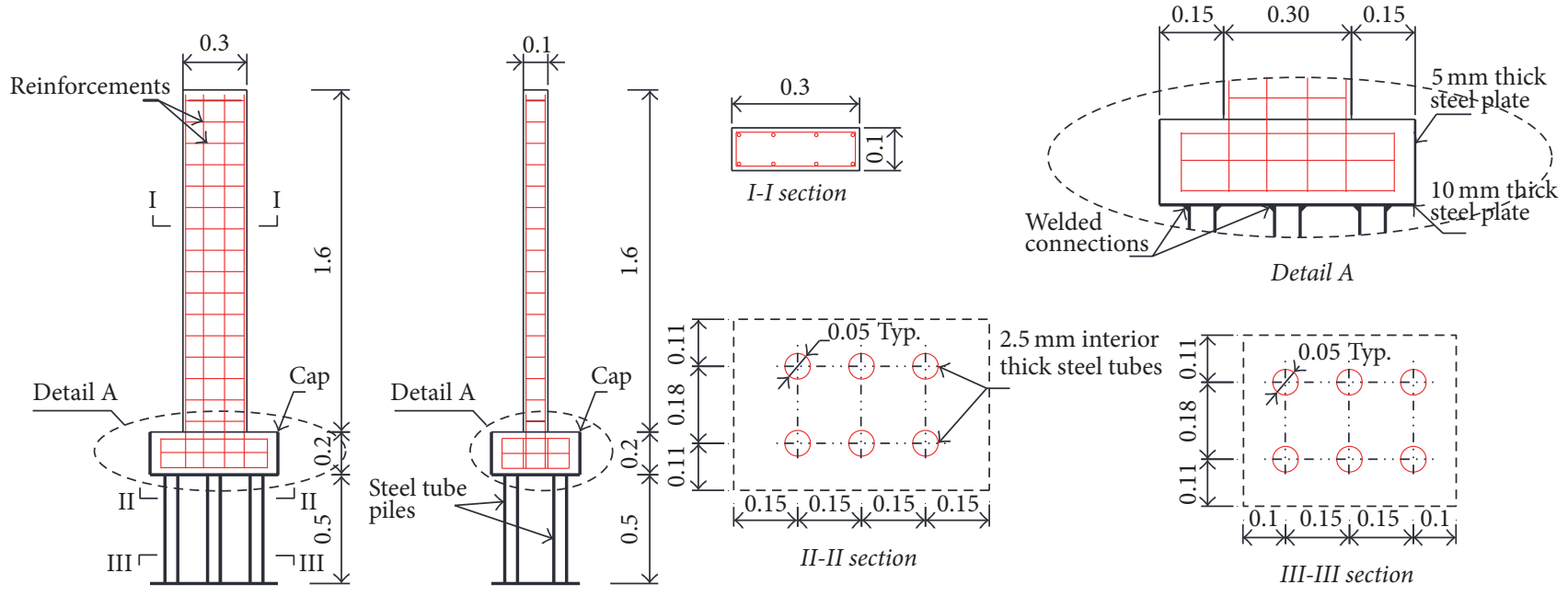

FIGURE 4: Dimensions and details of the pier specimen; all dimensions are in meters unless otherwise specified.

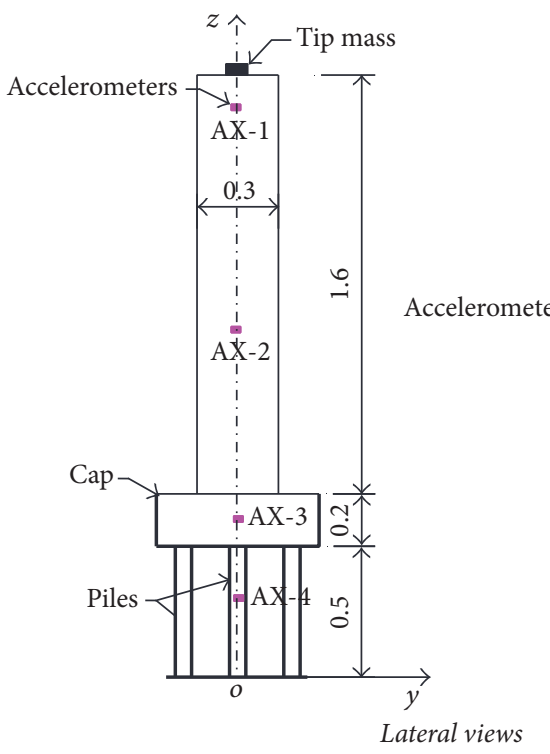

(a)

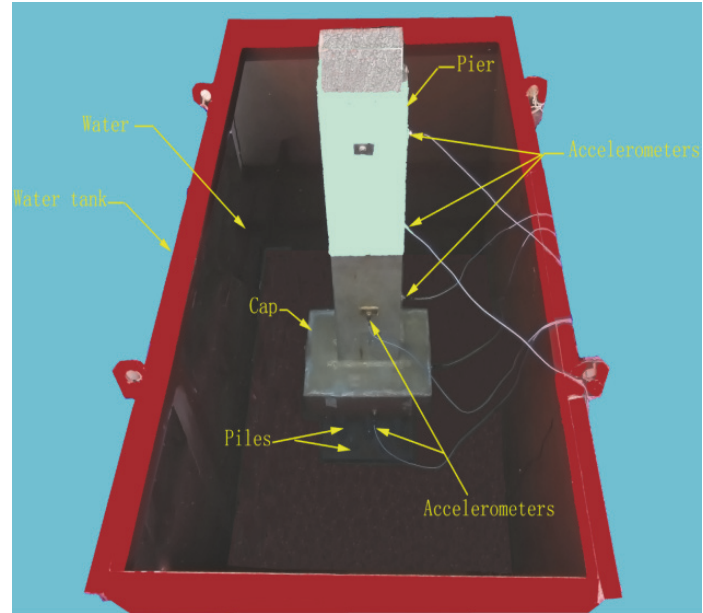

(b)

FIGURE 5: Measurement setup: (a) locations of the eight accelerometers mounted on the specimen; (b) picture of the testing setup.

2.4. Modal Parameter Identification. Using the eight accelerometers installed on the specimen, acceleration signals were acquired when the specimen was excited repeatedly for different water levels and tip masses based on forced vibration method. The acquired time-domain signals were transformed into frequency-domain information through the Fast Fourier Transform method (FFT), and a curve of power spectral density (PSD) was then obtained for each acceleration signal. Each spike of a PSD curve corresponds to a vibration frequency of the specimen. Since the four accelerometers arranged along $x$-axis (or $y$-axis) provided consistent frequency information for the same vibration mode with the difference in signal strength (or the height of the spikes on the curves), the time-domain acceleration signals, as well as the corresponding PSD curves, recorded by the accelerometers located at the top of the specimen are presented illustratively in the following in order to save space.

Figure 6 depicts the time-domain acceleration signals monitored by the top accelerometers when the specimen without tip mass was excited along $x$ - and $y$-axes, respectively, with an empty (i.e., $H_{\mathrm{w}}=0 \mathrm{~m}$ ) and full (i.e., $H_{\mathrm{w}}=$ $1.8 \mathrm{~m}$ ) water tank, respectively. And the corresponding PSD curves are shown in Figure 7, from which the vibration frequencies can be read directly according to the spike locations on the curves. For both axes, the obtained frequencies, when arranged in an increasing sequence, correspond to the lateral vibration modes of the specimen in the same sequence. As seen in Figure 7, the vibration frequencies of the specimen submerged in a full water tank are much smaller when compared with those obtained in an empty water tank. 


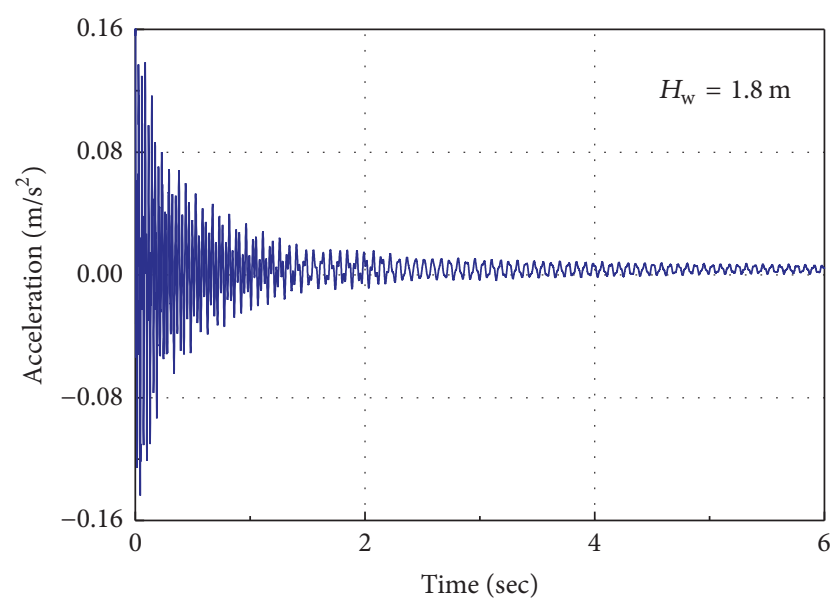

(a)

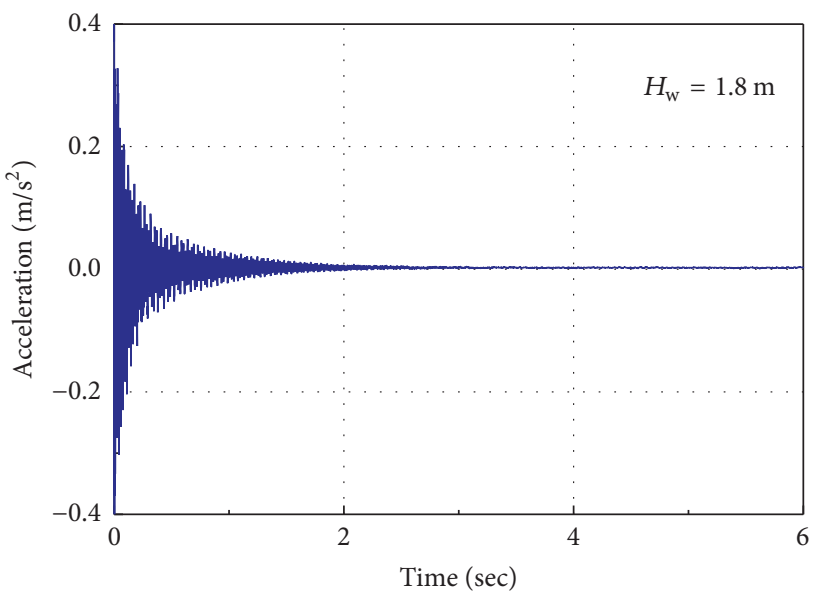

(c)

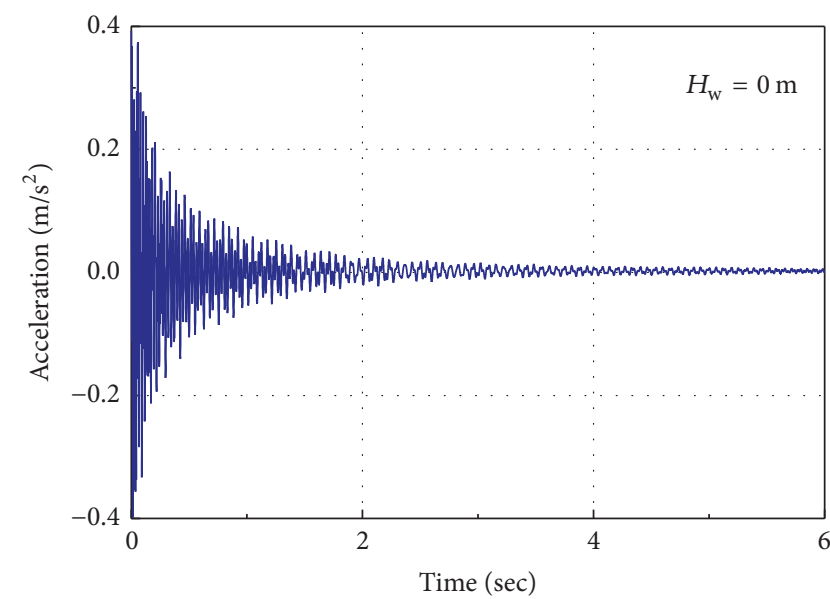

(b)

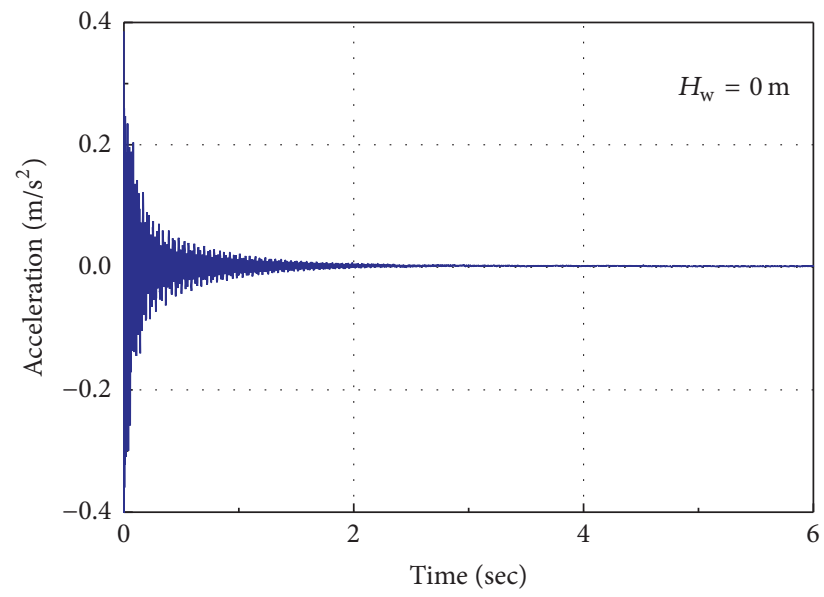

(d)

FIGURE 6: Acceleration signals acquired by the top accelerometers for the specimen without tip mass, corresponding to (a) $H_{\mathrm{w}}=1.8 \mathrm{~m}$ along $x$-axis; (b) $H_{\mathrm{w}}=0 \mathrm{~m}$ along $x$-axis; (c) $H_{\mathrm{w}}=1.8 \mathrm{~m}$ along $y$-axis; (d) $H_{\mathrm{w}}=0 \mathrm{~m}$ along $y$-axis.

\section{Numerical Simulations}

3.1. Fluid-Structure Interaction Formulation. In a fluid-structure system, the vibration of structure leads to water flow normal to its boundaries which produces additional hydrodynamic pressure acting on the structure. It is well known that the $\phi-U$ formulation can be used to characterize the procedure of fluid-structure interaction. In the $\phi-U$ formulation, $U$, representative of displacement, is used as a state variable in the solid domain and $\phi$, representative of velocity potential, is used in the fluid domain. The fluid is assumed to be inviscid, compressible, or incompressible, with an irrotational motion and relatively small displacements on the fluid-structure boundaries. The wave equation is written as

$$
\nabla^{2} \phi=\frac{1}{C_{\mathrm{w}}^{2}} \frac{\partial^{2} \phi}{\partial t^{2}}
$$

in which $C_{\mathrm{w}}$ is velocity of compressive waves within water and $t$ is time variable. In order to solve (1) in the background of a water-surrounded slender bridge pier with pile foundation, the following boundary conditions are specified for the velocity potential $\phi$ :

(i) An essential boundary condition at the free surface and the four lateral and bottom rigid walls of the water tank

$$
\phi=0
$$

(ii) A natural boundary condition at fluid-structure interfaces, including the water-piles, water-cap, and waterpier body interfaces

$$
\frac{\partial \phi}{\partial n}=\dot{u}_{n}
$$

where $\dot{u}_{n}$ is positive normal velocity corresponding to unit surface normal vector $\mathbf{n}$ pointing into the water bank and out of the structure. 


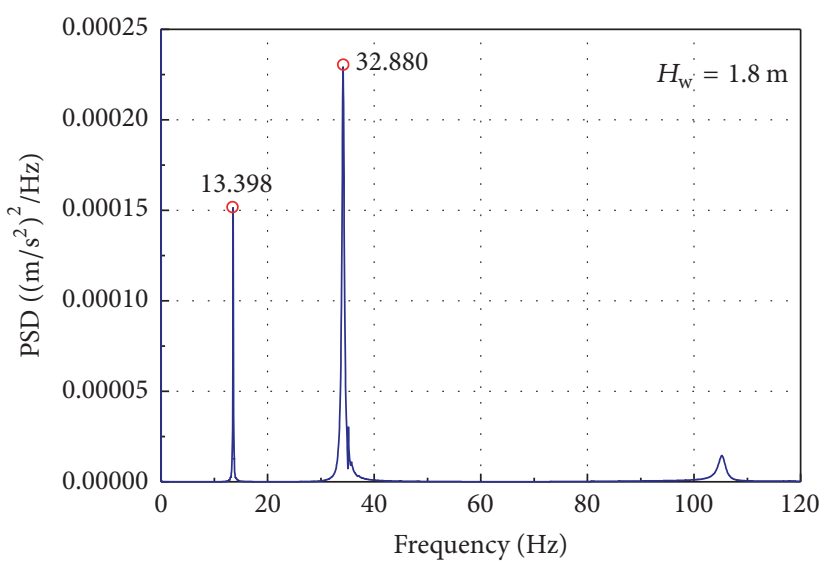

(a)

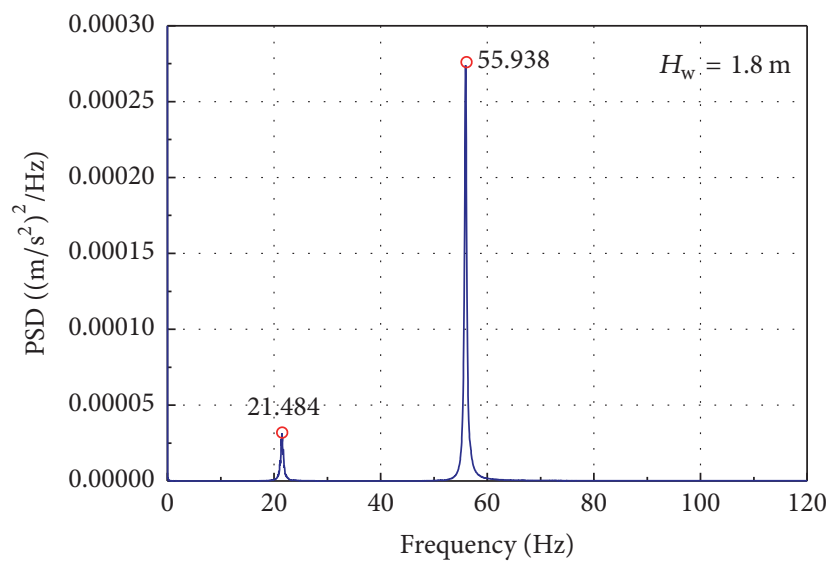

(c)

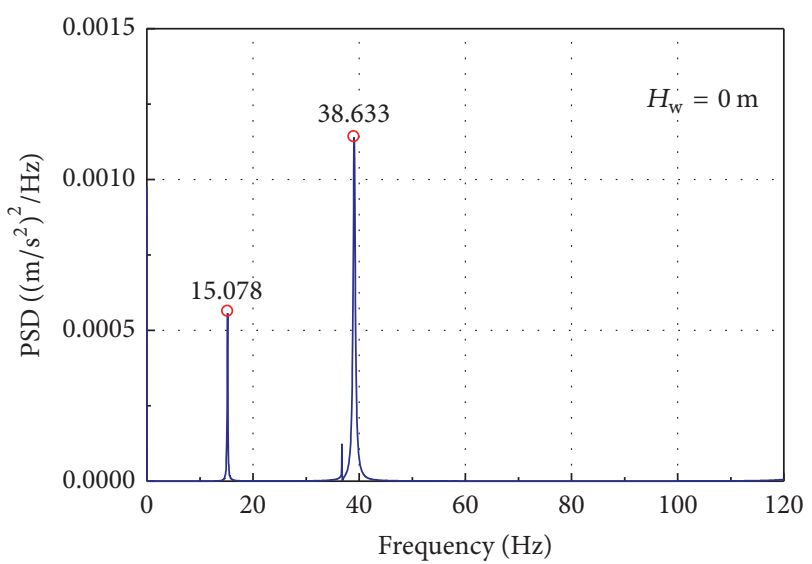

(b)

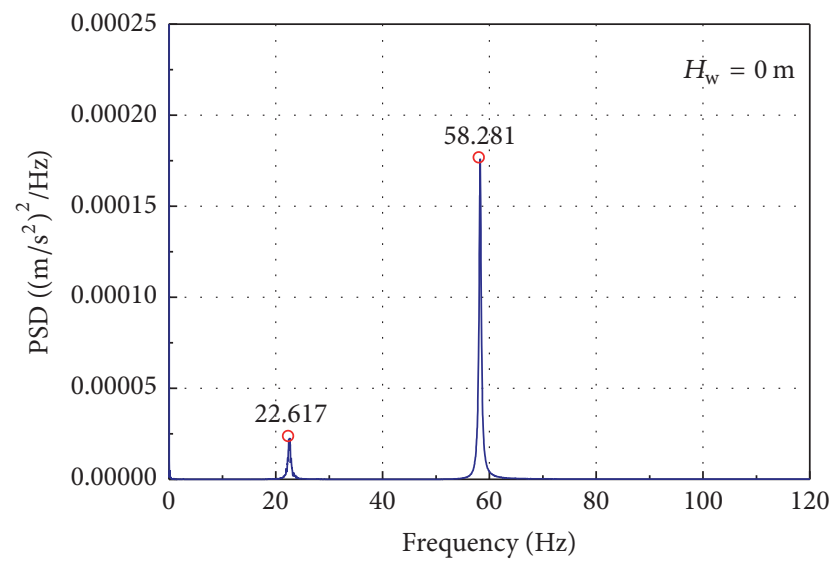

(d)

Figure 7: Power spectral density curves transformed from the acceleration signals shown in Figure 6, corresponding to (a) $H_{\mathrm{w}}=1.8 \mathrm{~m}$ along $x$-axis; (b) $H_{\mathrm{w}}=0 \mathrm{~m}$ along $x$-axis; (c) $H_{\mathrm{w}}=1.8 \mathrm{~m}$ along $y$-axis; (d) $H_{\mathrm{w}}=0 \mathrm{~m}$ along $y$-axis.

Equation (1) can be derived through standard techniques and discretized to obtain the following nonstandard eigenvalue problem:

$$
\begin{gathered}
\left(-\widetilde{\boldsymbol{\omega}}_{j}^{2}\left[\begin{array}{cc}
\mathbf{M}_{\mathrm{ss}} & \mathbf{0} \\
\mathbf{0} & \mathbf{M}_{\mathrm{ff}}
\end{array}\right]-\widetilde{\boldsymbol{\omega}}_{j}\left[\begin{array}{cc}
\mathbf{0} & \mathbf{C}_{\mathrm{fs}}^{T} \\
\mathbf{C}_{\mathrm{fs}} & \mathbf{0}
\end{array}\right]+\left[\begin{array}{cc}
\mathbf{K}_{\mathrm{ss}} & \mathbf{0} \\
\mathbf{0} & \mathbf{K}_{\mathrm{ff}}
\end{array}\right]\right) \\
\cdot\left[\begin{array}{c}
\mathbf{U}^{(j)} \\
-i \boldsymbol{\Phi}^{(j)}
\end{array}\right]=\left[\begin{array}{l}
\mathbf{0} \\
\mathbf{0}
\end{array}\right]
\end{gathered}
$$

in which $\widetilde{\boldsymbol{w}}_{j}$ is coupled frequency of the pier specimen along mode $j ; \mathbf{M}_{\mathrm{ss}}$ is structural mass matrix of the pier specimen; $\mathbf{M}_{\mathrm{ff}}$ is potential energy matrix of water domain; $\mathrm{C}_{\mathrm{fs}}$ is matrix coupling the velocity potential to displacements on the fluid-structure interfaces; $\mathbf{K}_{\mathrm{ss}}$ is stiffness matrix of the pier specimen; $\mathbf{K}_{\mathrm{ff}}$ is kinetic energy matrix of water domain; $\mathbf{U}^{(j)}$ is modal displacement eigenvector; $i=\sqrt{-1} ; \boldsymbol{\Phi}^{(j)}$ is fluid potential eigenvector.

Equation (4) is a nonstandard eigenvalue problem in which all of the eigenvalues are real and nonnegative. It can be solved using either the Determinant Search method or the Lanczos Iteration method.
3.2. FE Models. Three-dimensional (3D) finite-element models are established using the software ADINA [29] to model the tested pier specimen and surrounding water. The purpose is to compare the results obtained experimentally and numerically, respectively, and to validate the numerical procedures used widely to explore the dynamic characteristics of fluidstructure interaction. As illustrated in Figure 8, the 8-node shell finite elements programmed in ADINA are used to model the steel tube piles, and the 20-node solid finite elements are used to model the rest of the specimen including the pier body and pile cap. The tip masses are represented by the concentrated mass elements, and the water domain surrounding the specimen is meshed using the 20-node potential-based fluid elements. Fluid-structure interaction is accounted for through special elements defined at the water-structure interfaces. The bounding surfaces of the water domain are modeled using various types of potential interfaces defined as follows:

(i) Fluid-Structure. Place a fluid-structure potential interface on the boundary between a potential-based fluid and the adjacent structure, including water-pile, water-cap, and water-pier body interfaces. 


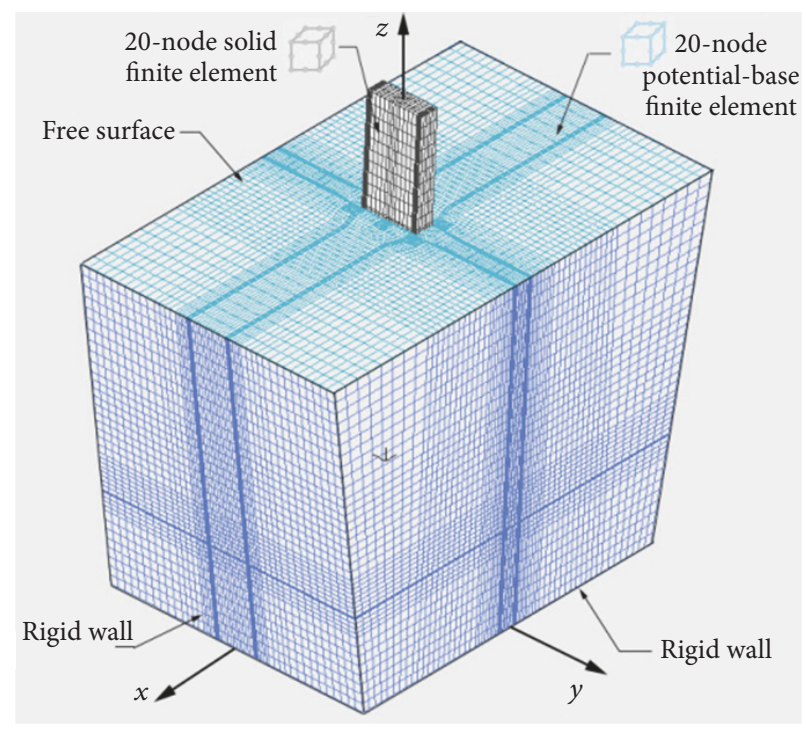

(a)

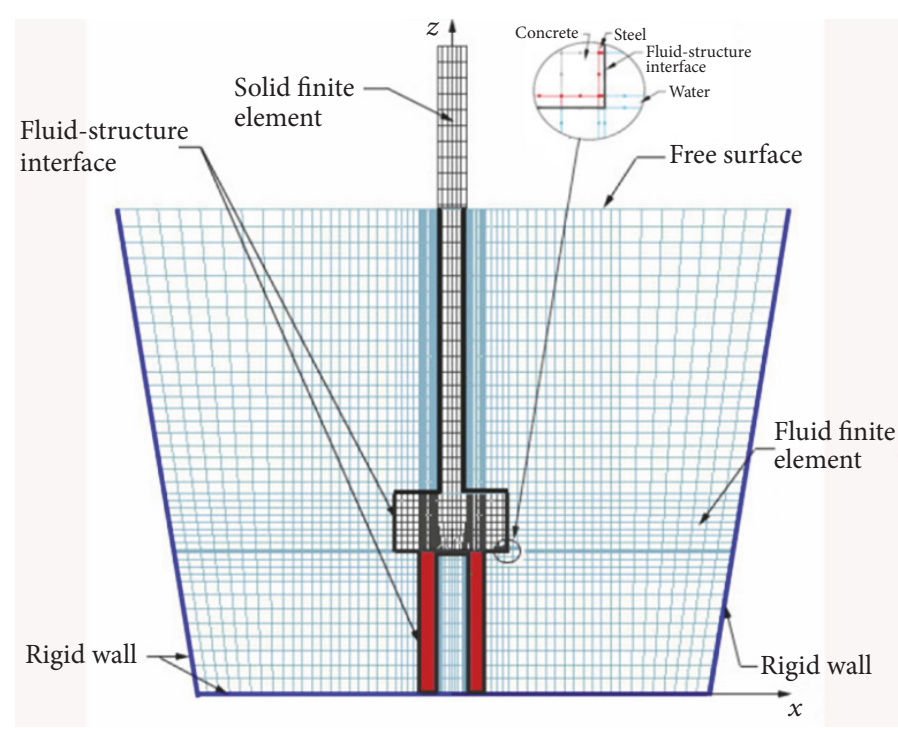

(b)

FIGURE 8: Finite-element model of the pier specimen and surrounding water: (a) overview; (b) elevation view through a central cutting plane.

(ii) Free Surface. Place a free surface potential interface on the top surface of the water domain, which can provide an approximate representation of the water surface waves.

(iii) Rigid-Wall. Place a rigid-wall potential interface on the bottom and the lateral surfaces where the water cannot flow through the boundary.

As explained above, the interface elements are used on the surface of the water domain to define specified boundary conditions. In general, the software ADINA can automatically generate fluid-structure interface elements along the boundary between the fluid and structure.

The material properties considered in the numerical simulations are given as follows: an elasticity modulus, $\mathbf{E}_{\mathrm{c}}$, of $22 \mathrm{GPa}$, a Poisson ratio, $\mathbf{v}_{\mathrm{c}}$, of 0.2 , and a mass density, $\boldsymbol{\rho}_{\mathrm{c}}$, of $2,300 \mathrm{~kg} / \mathrm{m}^{3}$ for concrete used to construct the pier body and pile cap and an elasticity modulus, $\mathbf{E}_{\mathrm{s}}$, of $210 \mathrm{GPa}$, a Poisson ratio, $\mathbf{v}_{\mathrm{s}}$, of 0.3 , and amass density, $\boldsymbol{\rho}_{\mathrm{s}}$, of $7,830 \mathrm{~kg} / \mathrm{m}^{3}$ for steel used to build the cap box and the steel tube piles. Water is assumed slightly compressible, with a velocity of compression waves, $\mathbf{C}_{\mathrm{w}}$, of $1,440 \mathrm{~m} / \mathrm{s}$ and a mass density, $\boldsymbol{\rho}_{\mathrm{w}}$, of $1,000 \mathrm{~kg} / \mathrm{m}^{3}$.

To improve the accuracy of the numerical simulations, the mesh densities of all the finite-element models were refined until convergence of the analyses. The maximum side length of the brick elements discretized for solid parts and fluid domain does not exceed $0.05 \mathrm{~m}$. It has been recommended that the fluid and adjacent structure do not share the coincident nodes because the software ADINA can construct appropriate constraint equations between the fluid and structural degrees of freedom that are most appropriate.

For each value of the tip mass, finite-element models were built for the dry structure, that is, without water, and the wet structures submerged by 15 water levels as shown in Figure 9.

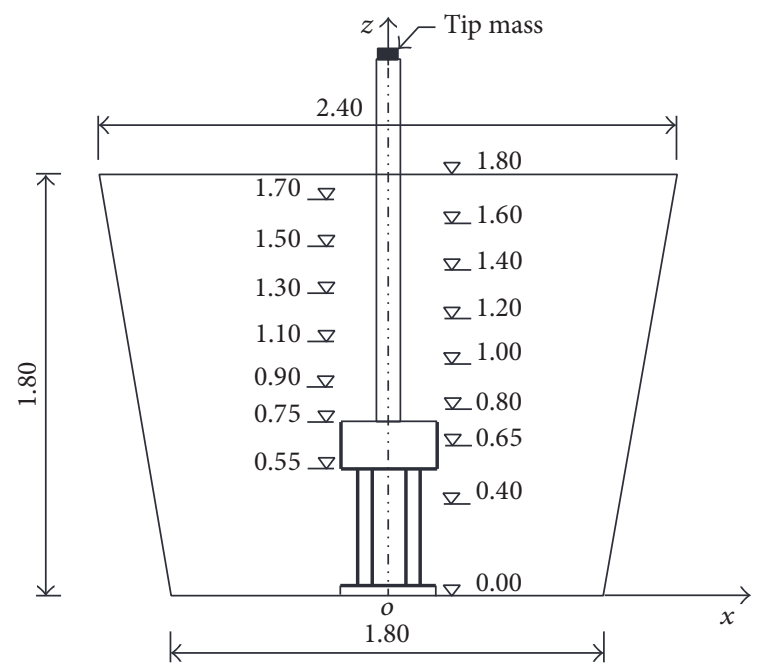

FIGURE 9: The 15 water levels considered in the tests; all dimensions are in meters.

And this produced a total of 64 finite-element models and 16 for each of the three tip masses as well as 16 for the case without tip mass.

3.3. Size Effect of the Water Tank. Based on previous research [30], the size of water tank plays a role in the modal dynamic response of structures. A small tank may obstruct the free propagation of water waves induced by vibration of structures and produce significant wave reflection at the tank's rigid walls, which in return affects the modal dynamic characteristics of the structures. In order to examine the adequacy of the size of the water tank adopted in the test, the effect of the size of the water tank on the test results is 


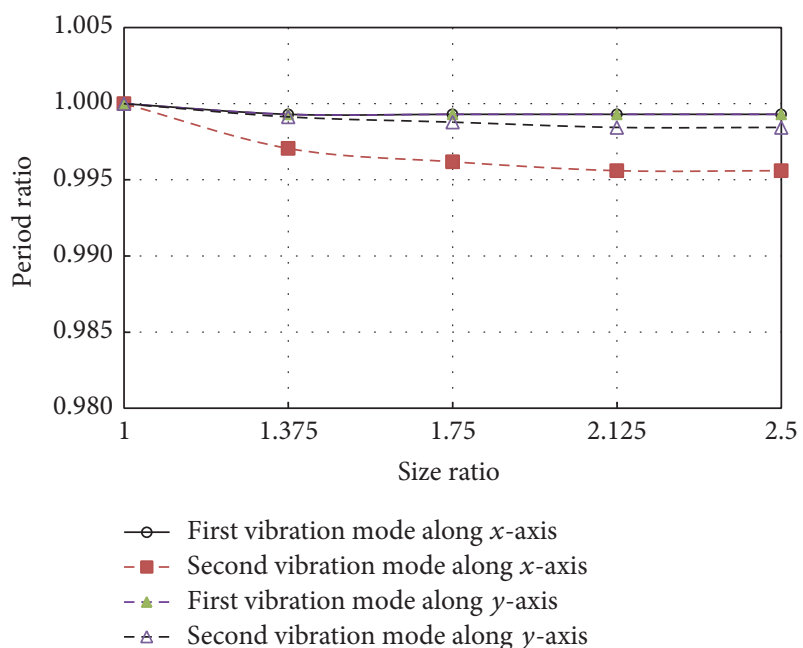

(a)

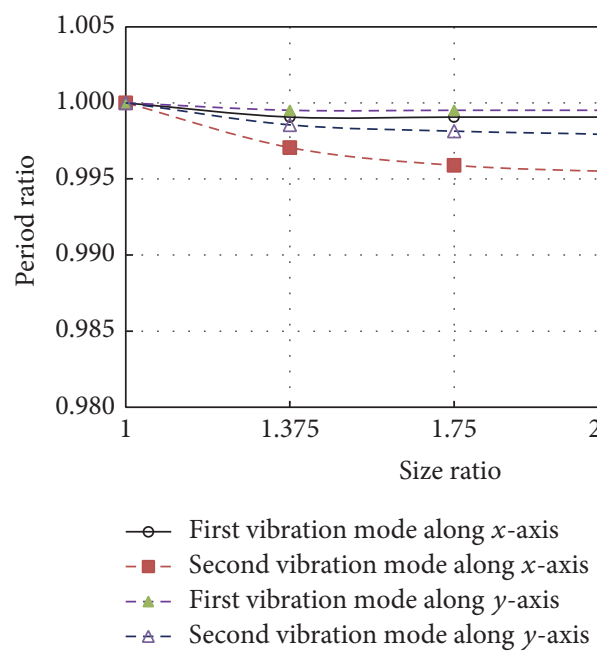

(c)

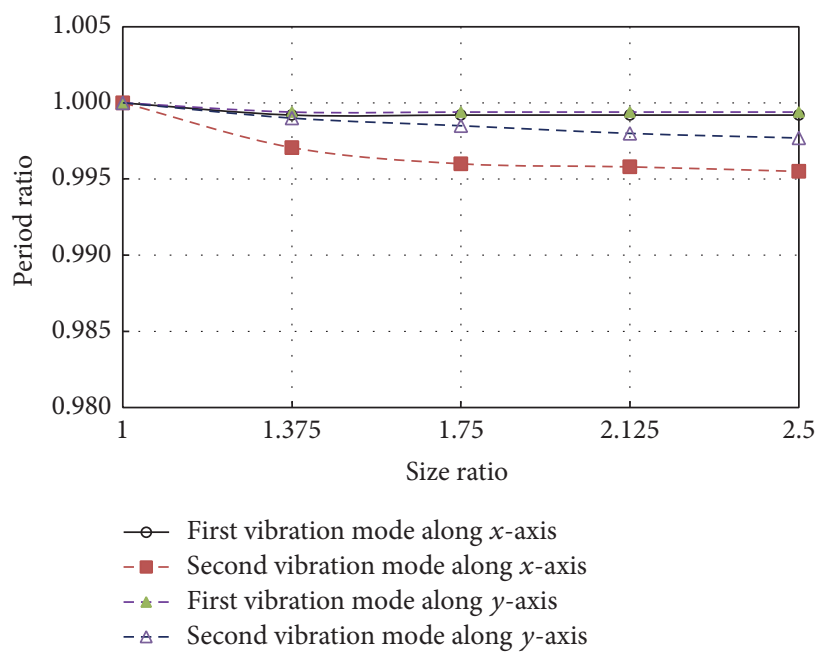

(b)

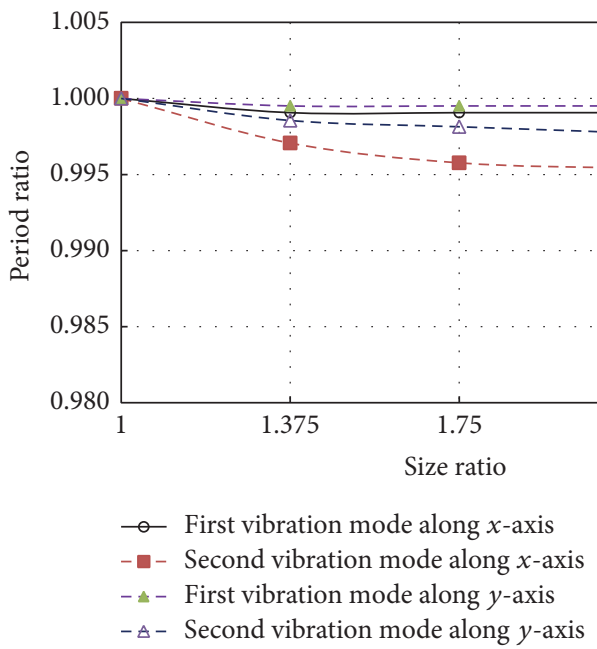

(d)

FIGURE 10: Computed mode period ratios, corresponding to a water level, $H_{\mathrm{w}}=1.8 \mathrm{~m}$, as a function of the size ratio of the water tank: (a) without tip mass; (b) with a tip mass of $12.1 \mathrm{~kg}$; (c) with a tip mass of $23.4 \mathrm{~kg}$; (d) with a tip mass of $31.7 \mathrm{~kg}$.

discussed in this section based on the finite-element models described previously.

Five size ratios of the water tank are considered herein, that is, $1.0,1.375,1.75,2.125$, and 2.5 , corresponding to $2.4,3.3,4.2,5.1$, and $6.0 \mathrm{~m}$ in length and $1.4,1.925,2.45$, 2.975 , and $3.5 \mathrm{~m}$ in width, respectively. The size ratio of 1.0 coincides with the tank dimensions adopted in the test, and the rest are the relative dimension ratios of the water tanks considered herein with respect to the water tank used in the test. Except the changes of the size of surrounding water domain, the other conditions and definitions applied in the numerical simulations remain the same as the model depicted in Figure 8.

Figure 10 presents the size effect of the water tank on the modal dynamic response of the specimen under four test cases. For brevity, only the results obtained from a full-filled water tank, that is, $H_{\mathrm{w}}=1.8 \mathrm{~m}$, are illustrated in Figure 10. It can be found that the first mode vibration periods of the specimen along $x$-axis and $y$-axis almost remain the same as the size ratio of the tank increases. The second modes of vibration along $x$-axis and $y$-axis decrease slowly with the increase of size ratio, and the maximum decrease is not more than $0.5 \%$ with reference to the periods obtained using the size ratio 1.0. It is evident that the size ratio of the water tank, considered herein, has little effect on the modal dynamic response of the specimen, indicating that the dimensions of the tank adopted in the test were sufficient to minimize the influence of boundary reflection.

\section{Comparison and Discussion of Experimental and Numerical Results}

4.1. Percentage Increases of Vibration Periods. In order to discuss the effect of fluid-structure interaction on the modal dynamic response of the specimen, percentage increases of vibration periods are applied herein to show the tendency of 
the specimen vibration period in different test cases where the water levels varied from 0 to $1.8 \mathrm{~m}$ (from an empty to full tank, as shown in Figure 9) and the tip masses altered from 0 to $31.7 \mathrm{~kg}$ (i.e., $0,12.1,23.4$, and $31.7 \mathrm{~kg}$ ), respectively. The vibration periods $T_{x j}^{\mathrm{wo}}$ and $T_{y j}^{\mathrm{wo}}, j=1,2$, are the results of the specimen without water, corresponding to the first two modes along $x$-axis and $y$-axis, respectively. The vibration periods $T_{x j}^{\mathrm{W}}, j=1,2$, and $T_{y j}^{\mathrm{w}}, j=1,2$, correspond to the first two modes along $x$-axis and $y$-axis, respectively, which were determined for each water level considered in this paper. The percentage increases of vibration periods $\operatorname{Inc} T_{x j}=\left(T_{x j}^{\mathrm{w}}-\right.$ $\left.T_{x j}^{\mathrm{wo}}\right) / T_{x j}^{\mathrm{wo}}$ and Inc $T_{y j}=\left(T_{y j}^{\mathrm{w}}-T_{y j}^{\mathrm{wo}}\right) / T_{y j}^{\mathrm{wo}}, j=1,2$, were then obtained for each tip mass.

For each combination of water level and tip mass, the first four lateral modes, including the first two modes along $x$-axis and the first two modes along $y$-axis, could be excited using the forced vibration method. Higher orders of mode are not easy to be excited in a steady condition based on traditional forced vibration tests, and they were not the major concern of this experimental research. The torsional mode was not taken into consideration during the tests, because in most cases the torsional mode contributes little to the seismic response of bridges, especially to that of straight bridges. For illustration, Figure 11 shows the four lateral mode shapes of the slender pier specimen when the water tank is empty and the tip mass is zero.

Figures $12-15$ give the trends of the period percentage increases of the slender pier specimen with respect to the water level changing from 0 to $1.8 \mathrm{~m}$, for an empty to full water tank, in the four tip mass cases, respectively. Together with experimental results, the numerical results obtained using the finite-element models described previously are also presented in these figures. The figures manifest a satisfactory agreement between the numerical results and the experimental data for all combinations of water level and tip mass. It can be seen from these figures that the effect of fluid-structure interaction becomes more remarkable as the water level increases, and when the tank is full with water the period percentage increases of the four modes under the four tip masses reach the largest values. It is noticeable that the percentage increases along the $x$-axis are evidently larger than those along the $y$-axis, especially in the second vibration modes. This can be explained by the fact that the area of the pier specimen perpendicular to $x$-axis is larger than that perpendicular to $y$-axis, as shown in Figure 4, and therefore the fluid-structure potential interfaces perpendicular to the vibration direction are larger in $x$-axis, indicating that the effect of fluid-structure interaction becomes more significant in $x$-axis.

The curves of the period percentage increases versus water levels can be divided into three zones, as depicted in Figures 12-15. In Zone I where the water level is below the pile cap, that is, $H_{\mathrm{w}}<55 \mathrm{~cm}$, the period percentage increases of the four modes under the four tip masses remain practically unchanged, implying that the hydrodynamic effect of water-piles interaction is negligibly weak when bridges are submerged by water up to the bottom of pile caps. In Zone II where the water level is just over the entire height of the pile cap, that is, $55 \mathrm{~cm}<H_{\mathrm{w}}<75 \mathrm{~cm}$, the curves of the four modes

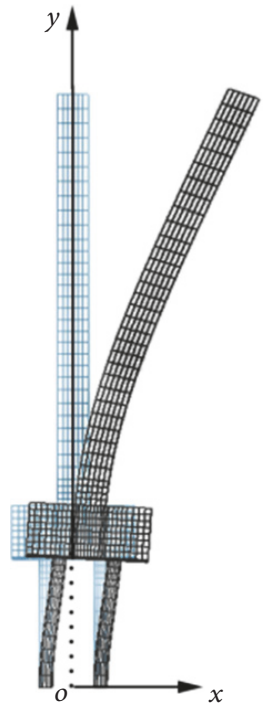

(a)

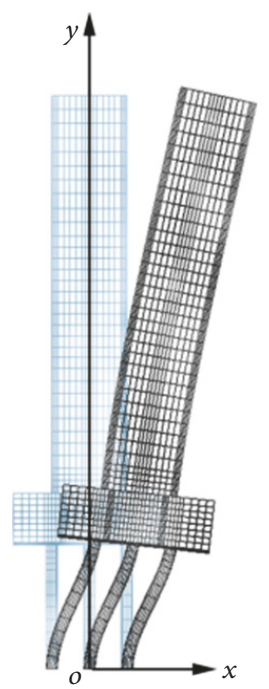

(c)

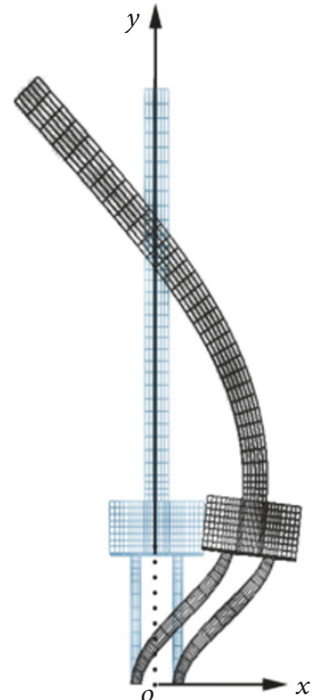

(b)

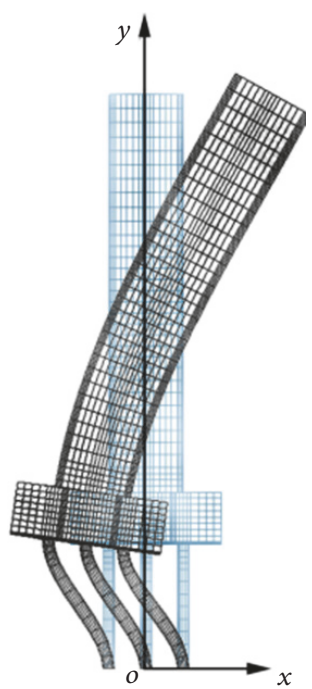

(d)
FIGURE 11: First four lateral mode shapes of the dry structure without tip mass: (a) first lateral mode along $x$-axis; (b) second lateral mode along $x$-axis; (c) first lateral mode along $y$-axis; (d) second lateral mode along $y$-axis.

under the four tip masses ascend obviously but limitedly, with a maximum value of around 1.05 among all the curves. The figures also tell that the first vibration modes are less influenced by the hydrodynamics when compared with higher order vibration modes. In Zone III where the pier body is submerged in water, that is, $H_{\mathrm{w}}>75 \mathrm{~cm}$, a continuous climb of the curves can be observed in the four modes under the four tip masses, especially in those along $x$-axis. And a different trend can be found between the results of first modes and second modes along $x$-axis for the four tip mass cases. With the increase of water levels, the period percentage increases of the second modes grow quickly in the beginning and then in a much slower pattern, whereas the period percentage increases of the first modes grow contrarily. 


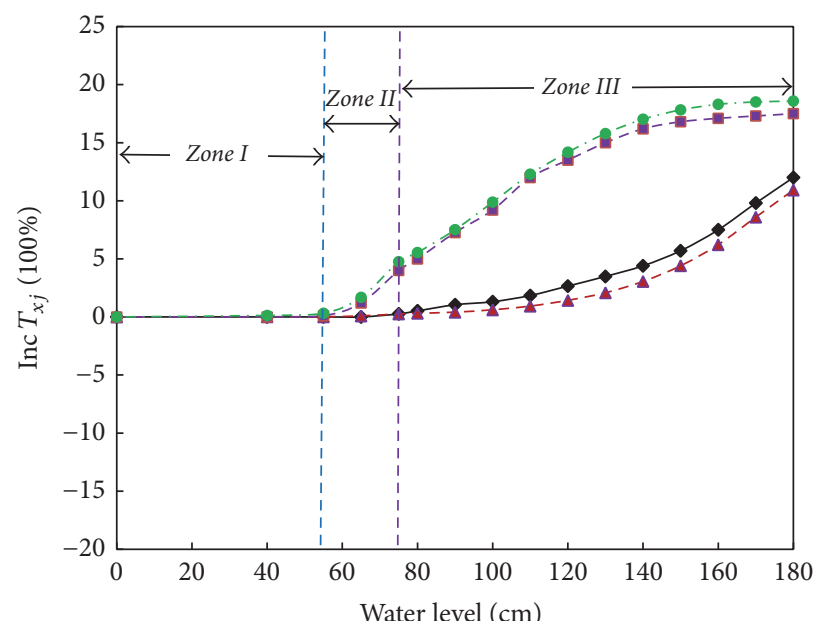

$\rightarrow$ Experimental results for first mode

- - Numerical results for first mode

- - Experimental results for second mode

$\rightarrow$ - Numerical results for second mode

(a)

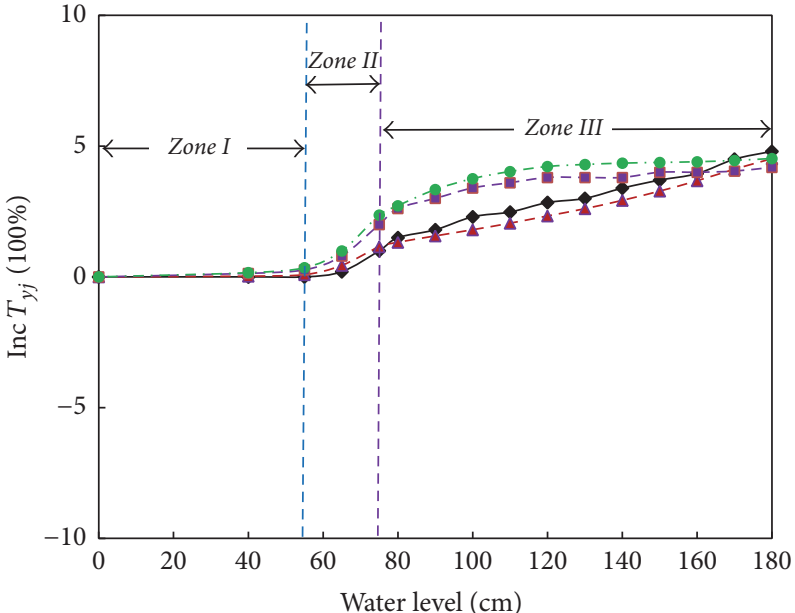

$\multimap$ Experimental results for first mode

- - Numerical results for first mode

- - Experimental results for second mode

- $\rightarrow$ Numerical results for second mode

(b)

FIGURE 12: Measured and computed period percentage increases for the pier specimen without tip mass as a function of water level: (a) the first two lateral modes along $x$-axis; (b) the first two lateral modes along $y$-axis.

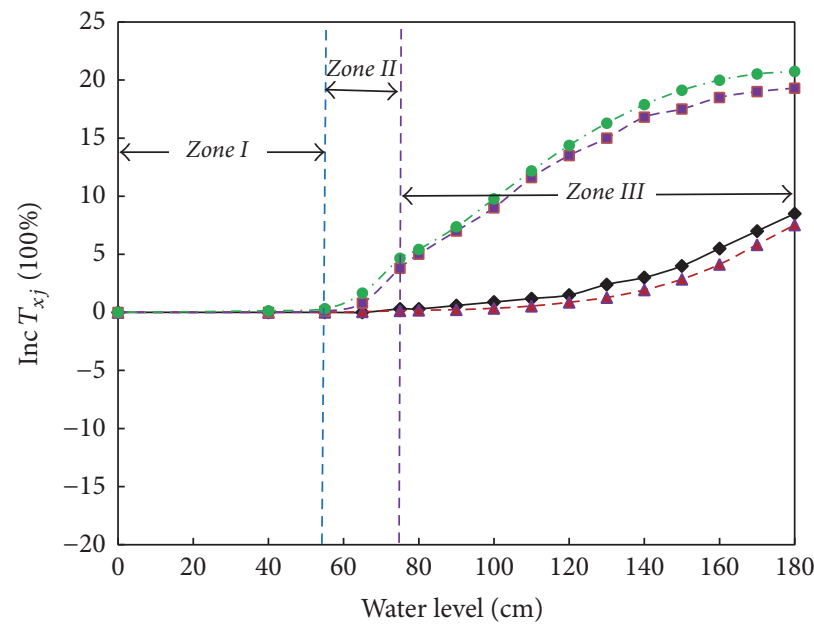

$\multimap$ Experimental results for first mode

- $\ldots$ - Numerical results for first mode

- - Experimental results for second mode

$\rightarrow$ - Numerical results for second mode

(a)

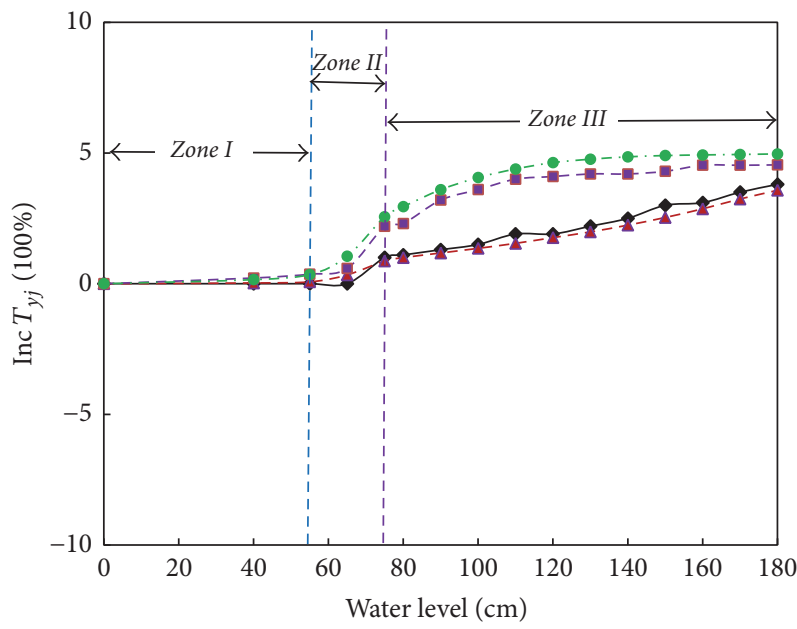

$\neg$ Experimental results for first mode

- $\ldots$ - Numerical results for first mode

- - Experimental results for second mode

- - - Numerical results for second mode

(b)

FIGURE 13: Measured and computed period percentage increases for the pier specimen with a $12.1 \mathrm{~kg}$ tip mass as a function of water level: (a) the first two lateral modes along $x$-axis; (b) the first two lateral modes along $y$-axis.

For clarity, the curves of the period percentage increases versus water levels for different tip masses are drawn together for each vibration mode, as shown in Figure 16. It is interesting to notice that the period percentage increases of the first modes for both directions decrease when the tip mass becomes larger, whereas the period percentage increases of the second modes show an opposite trend.
It is implied that the effect of fluid-structure interaction attenuates in the first modes but strengthens in higher order modes as the tip mass increases. It is worthwhile to point out that the period percentage increases along $x$ axis reach a maximum of $11.0 \%$ for the first mode and $22.7 \%$ for the second mode, both occurring when the water tank is full. It might be nonconservative to overlook the 


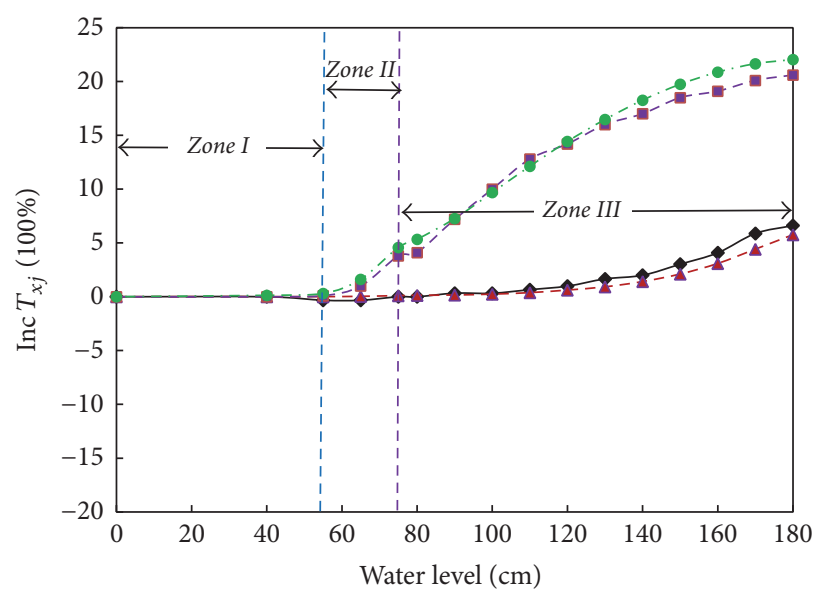

- Experimental results for first mode

- - Numerical results for first mode

- - Experimental results for second mode

$\rightarrow$ - Numerical results for second mode

(a)

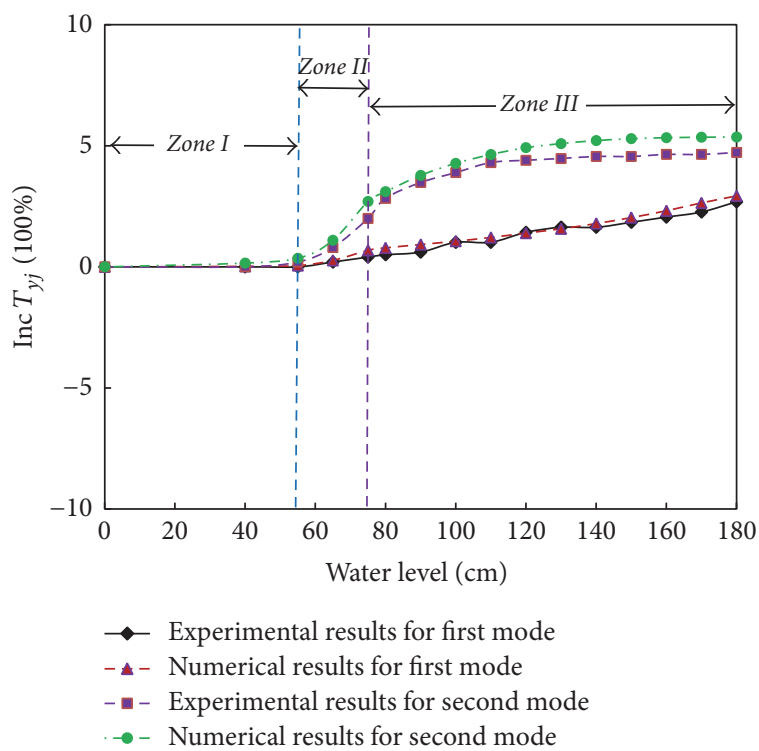

(b)

FIGURE 14: Measured and computed period percentage increases for the pier specimen with a $23.4 \mathrm{~kg}$ tip mass as a function of water level: (a) the first two lateral modes along $x$-axis; (b) the first two lateral modes along $y$-axis.

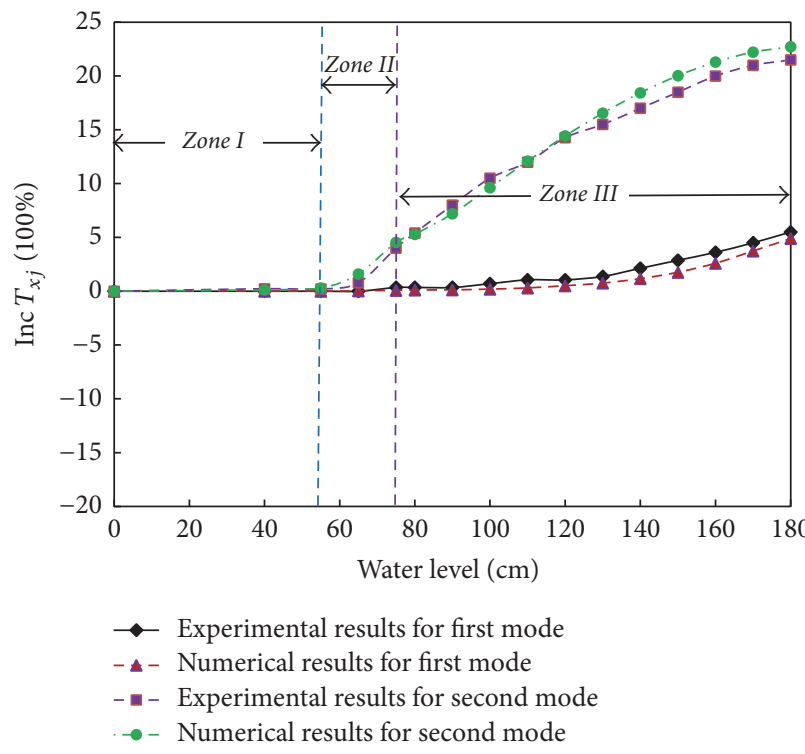

(a)

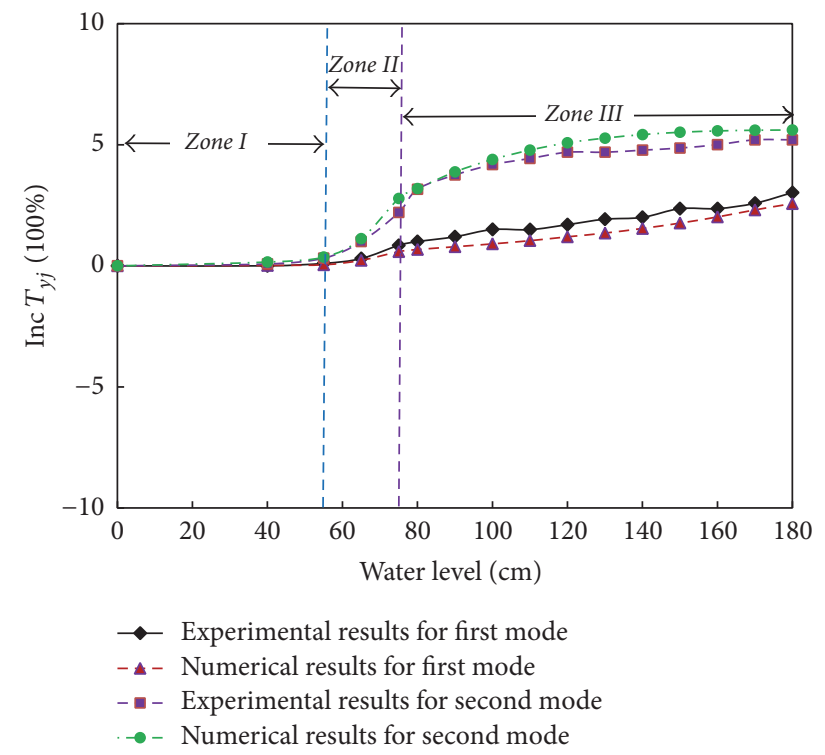

(b)

FIGURE 15: Measured and computed period percentage increases for the pier specimen with a $31.7 \mathrm{~kg}$ tip mass as a function of water level: (a) the first two lateral modes along $x$-axis; (b) the first two lateral modes along $y$-axis.

hydrodynamic loads during seismic or other dynamic analyses or design of bridges with high and slender piers surrounded by water.

4.2. Hydrodynamic Pressures. The hydrodynamic pressure acting on the surfaces of a structure is of great significance for the earthquake-resistant design of the structure. In this section, the hydrodynamic pressures on the surfaces of the specimen in different cases are presented to further investigate the effect of fluid-structure interaction. For the purpose of comparison between various cases in a uniform standard, the hydrodynamic pressures are nondimensionalized through scaling by the maximum hydrostatic pressure, $p_{\text {stat }}=\rho_{\mathrm{w}} g H_{\mathrm{w}}$. In application of the finite-element models described and validated previously, the modal hydrodynamic pressures are obtained and illustrated for each mode considered herein through two-dimensional (2D) contour maps along two cutting planes specially selected. For the sake of 


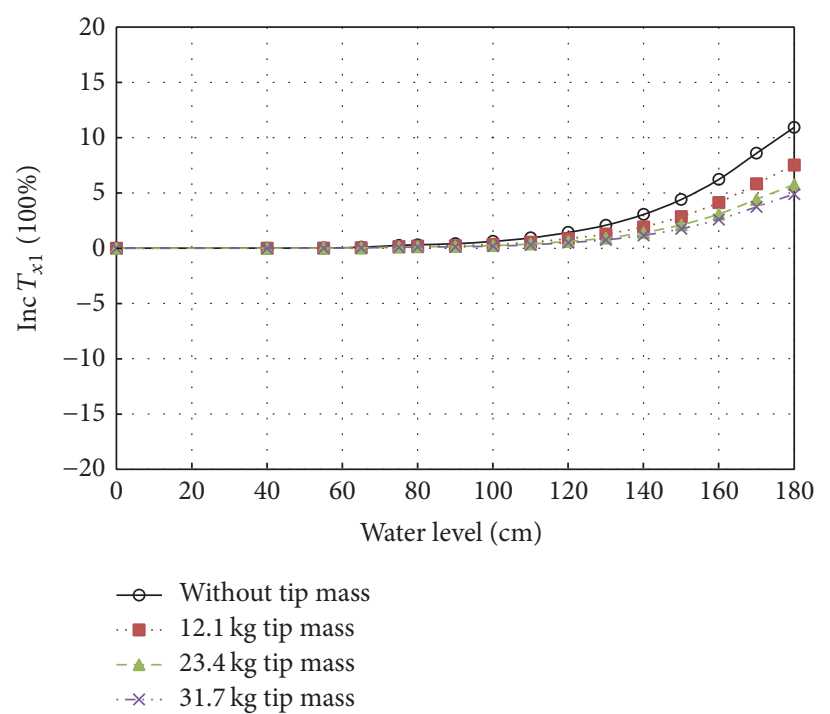

(a)

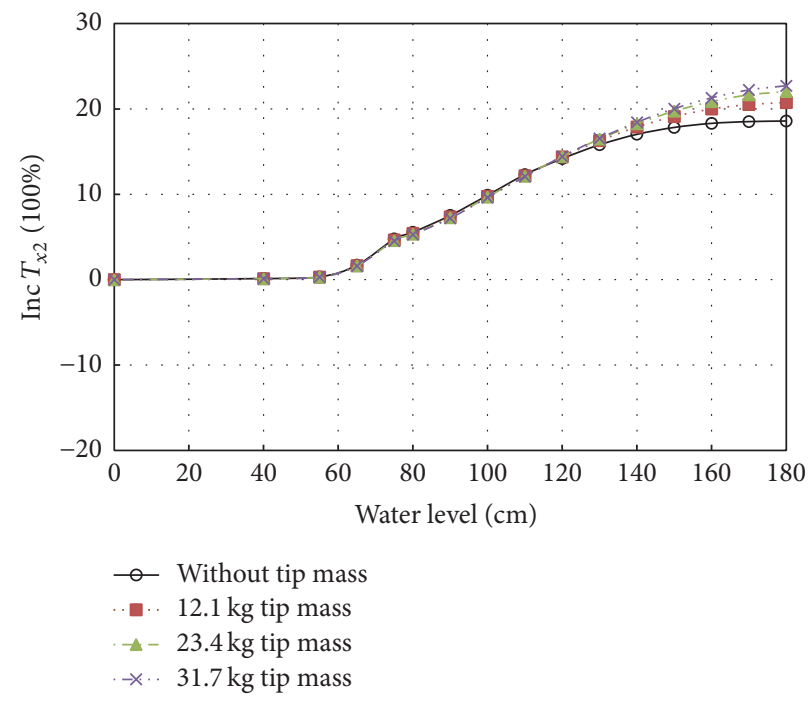

(c)

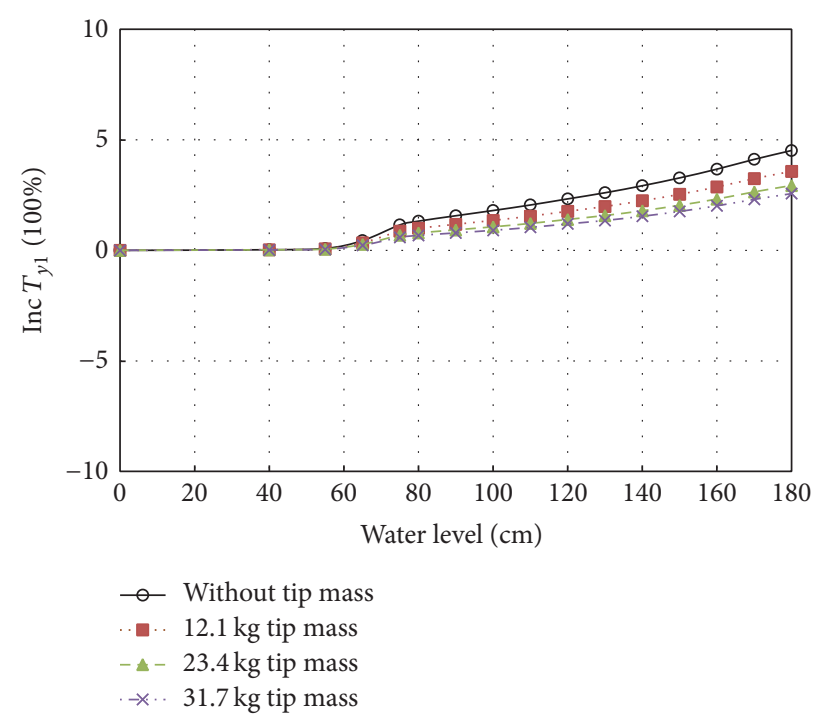

(b)

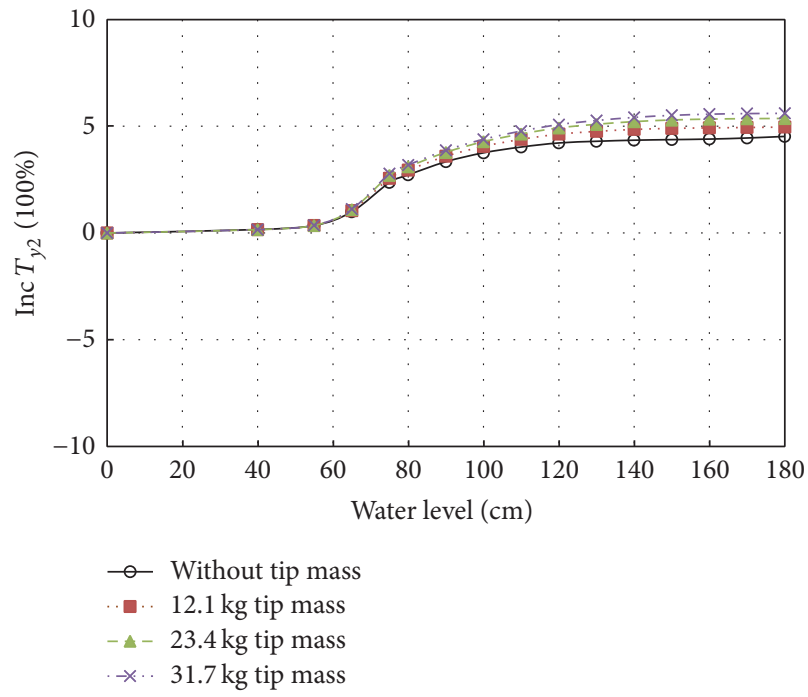

(d)

FIGURE 16: Computed period percentage increases for the pier specimen as a function of water level: (a) first mode along $x$-axis; (b) first mode along $y$-axis; (c) second mode along $x$-axis; (d) second mode along $y$-axis.

conciseness, only results for three water levels are chosen as illustrating examples in the following.

Figure 17 presents the nondimensionalized hydrodynamic pressures for the first mode along $x$-axis of the pier specimen without tip mass surrounded by three water levels, that is, $H_{\mathrm{w}}=1.2 \mathrm{~m}, H_{\mathrm{w}}=1.5 \mathrm{~m}$, and $H_{\mathrm{w}}=1.8 \mathrm{~m}$, respectively. The vertical cutting plane is selected as $y=0 \mathrm{~m}$ passing through the middle of the pier specimen and three horizontal cutting planes are selected as $z=1.55 \mathrm{~m}, z=1.25 \mathrm{~m}$, and $z=0.95 \mathrm{~m}$, respectively, each passing through the location of the maximum hydrodynamic pressure. Figures 17(a), 17(c), and $17(\mathrm{e})$ reveal that higher hydrodynamic pressures are mainly concentrated around the upper half of the submerged pier body and the pressures developed on the piles and cap are relatively lower compared with those on the pier body. The location of the recorded maximum pressure climbs accordingly with the increase of the water level. The effect of water levels can also be found in Figures 17(b), 17(d), and 17(f), from which it can be seen that the modal hydrodynamic pressures increase significantly as the water level rises from 1.2 to $1.8 \mathrm{~m}$. These phenomena can be used to explain the observation that the mode period ratios along $x$-axis increase remarkably along with the rising water level, as shown in Figure 12(a).

Figure 18 shows the nondimensionalized hydrodynamic pressures for the second mode along $x$-axis of the pier specimen without tip mass. The water levels are the same as given in Figure 17 and the cutting planes are selected using the same pattern as used in the first mode and defined previously. The figures give a somewhat opposite observation 


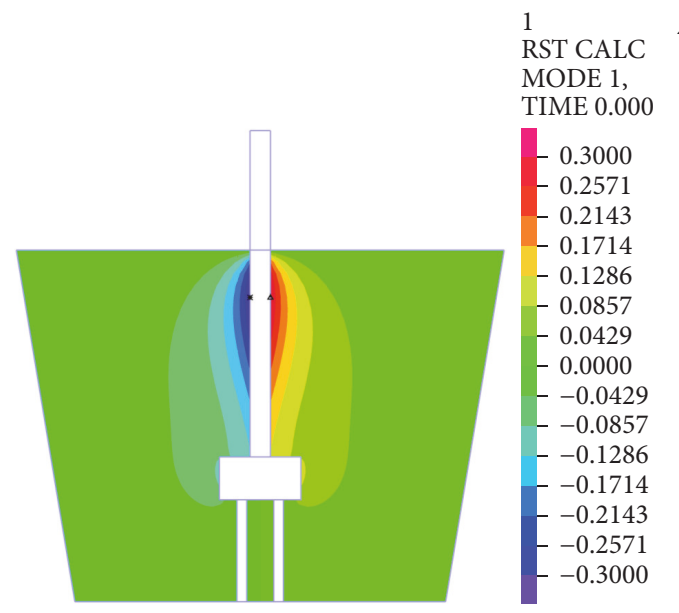

(a)

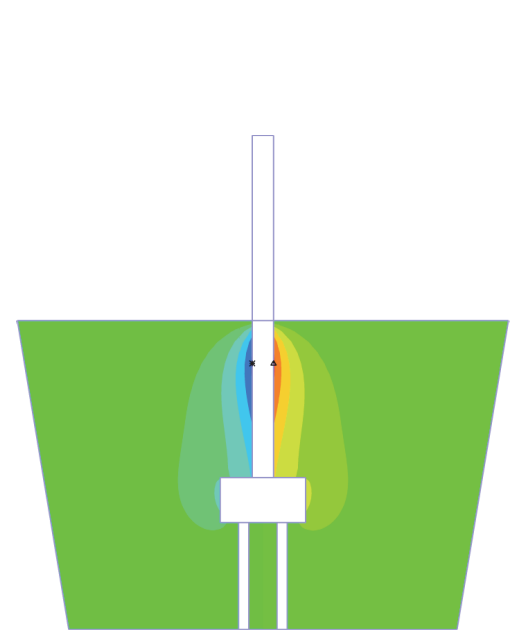

(c)
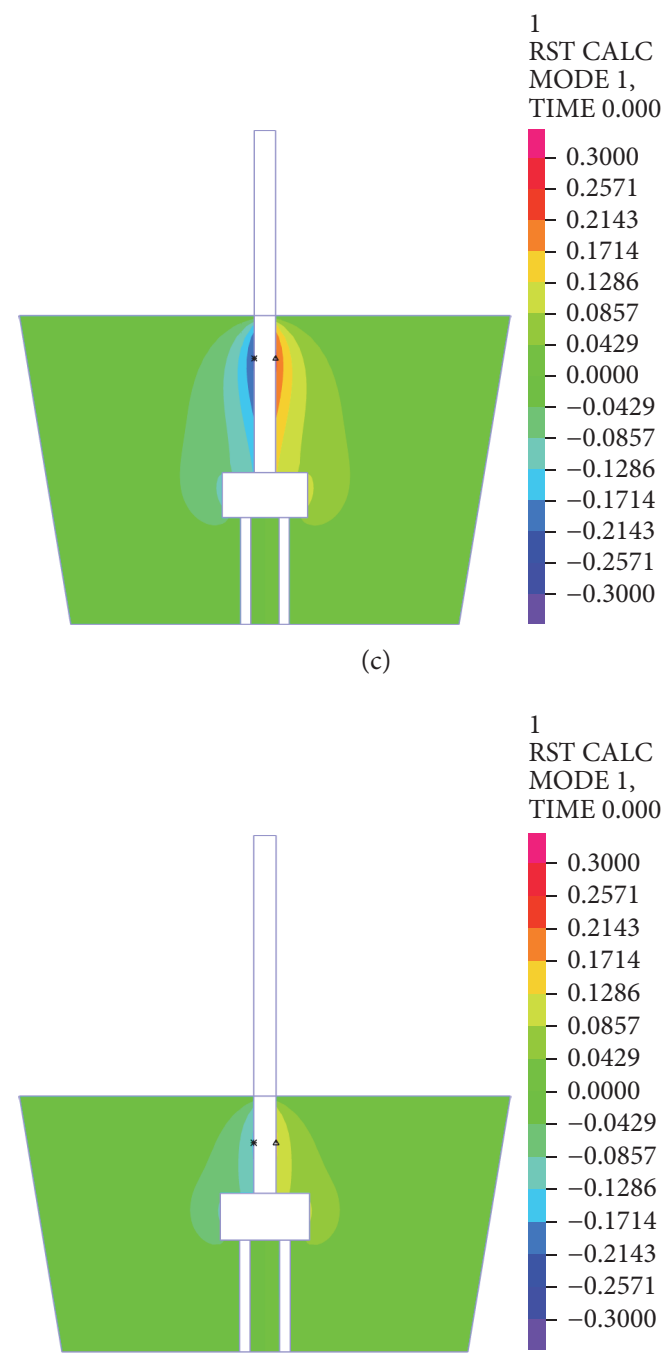

(e)

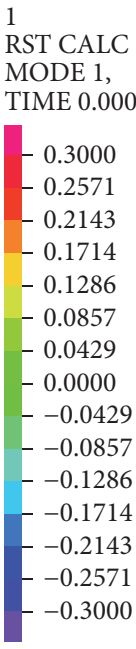

$-0.2571$

$-0.3000$
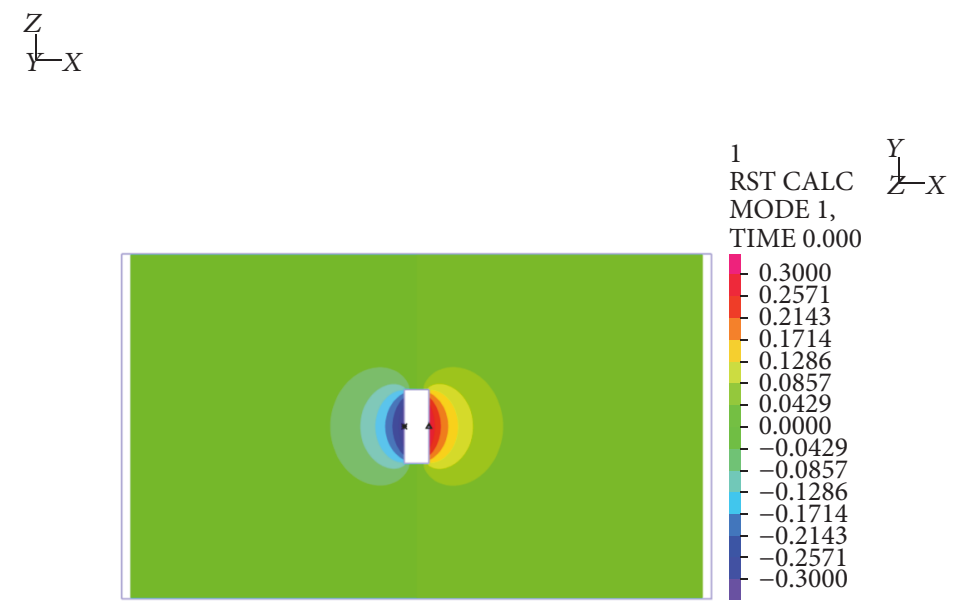

(b)
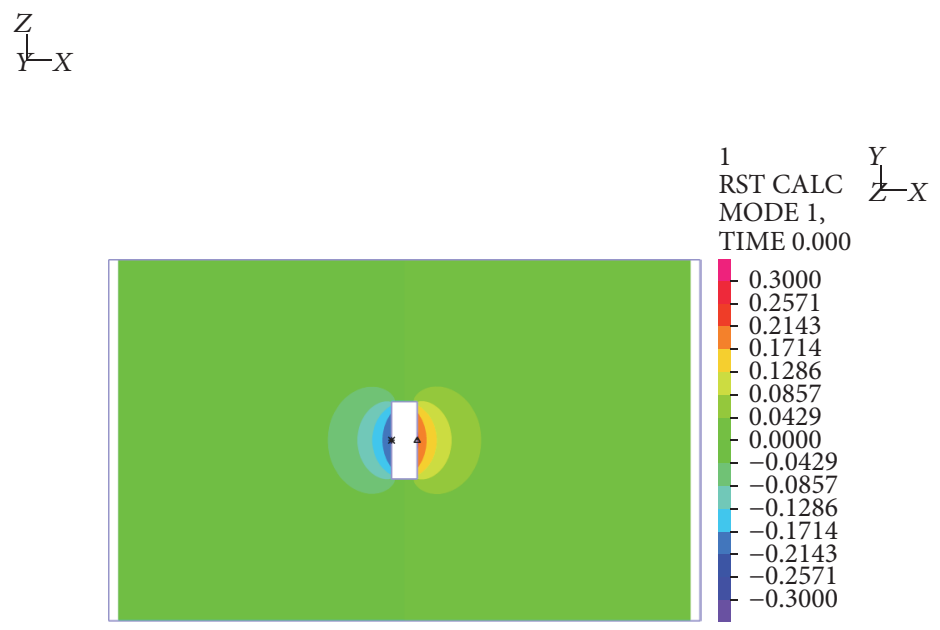

(d)

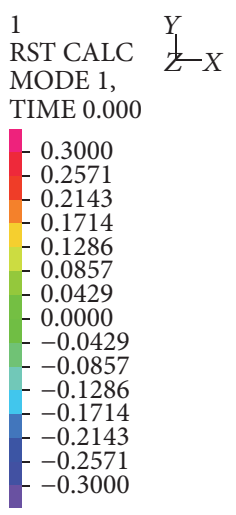

(f)

FIGURE 17: Nondimensional modal hydrodynamic pressures on the pier specimen without tip mass for the first mode along $x$-axis; profiles for a water level, $H_{\mathrm{w}}$, of $1.8 \mathrm{~m}$ along cutting planes: (a) $y=0 \mathrm{~m}$ and (b) $z=1.55 \mathrm{~m}$; profiles for a water level, $H_{\mathrm{w}}$, of $1.5 \mathrm{~m}$ along cutting planes: (c) $y=0 \mathrm{~m}$ and (d) $z=1.25 \mathrm{~m}$; profiles for a water level, $H_{\mathrm{w}}$, of $1.2 \mathrm{~m}$ along cutting planes: (e) $y=0 \mathrm{~m}$ and (f) $z=0.95 \mathrm{~m}$. 


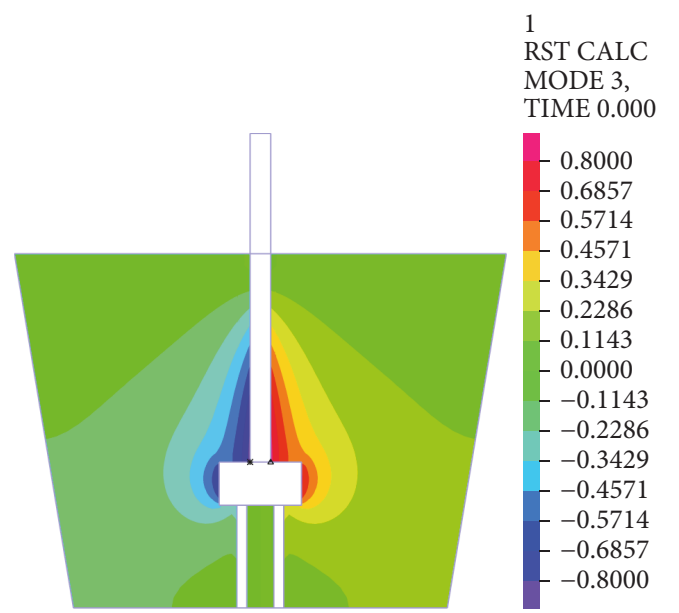

(a)

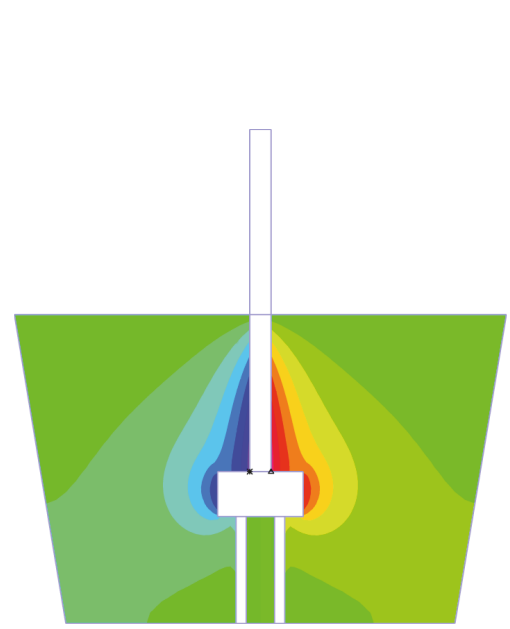

(c)

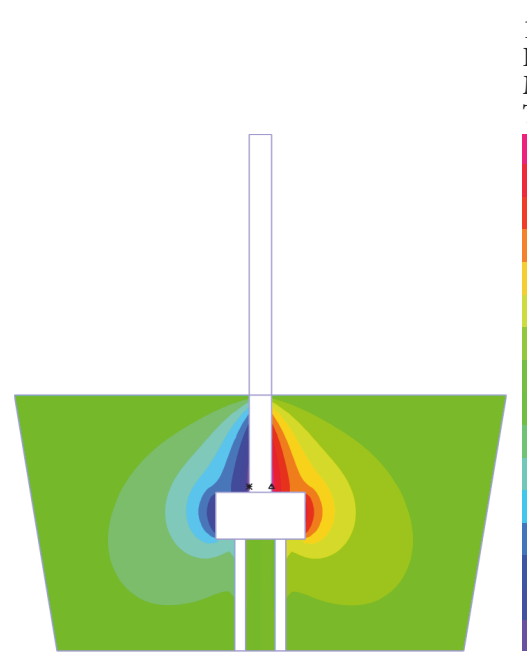

(e)

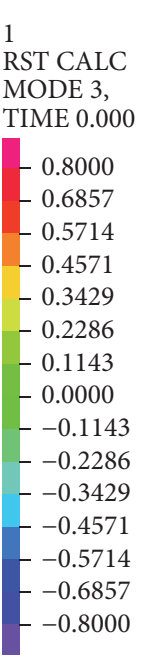

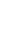

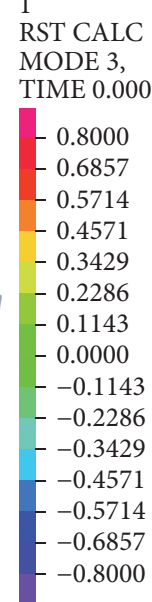

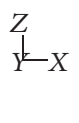

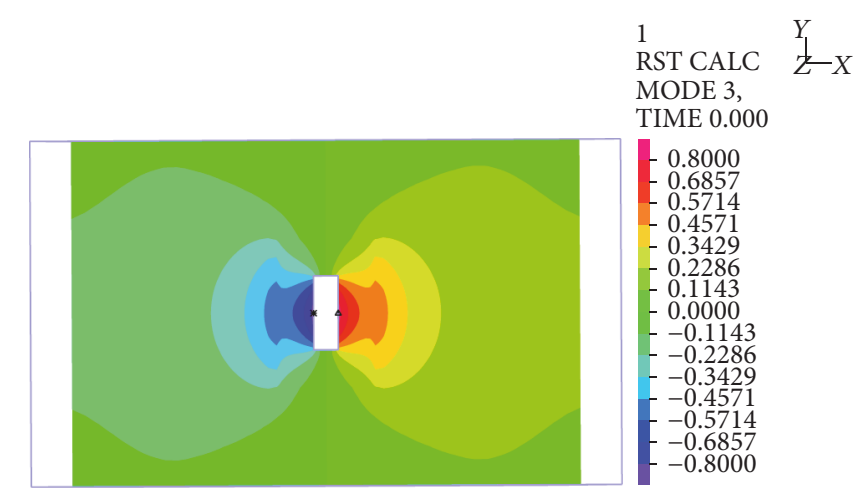

(b)

$Z$
$Y-X$

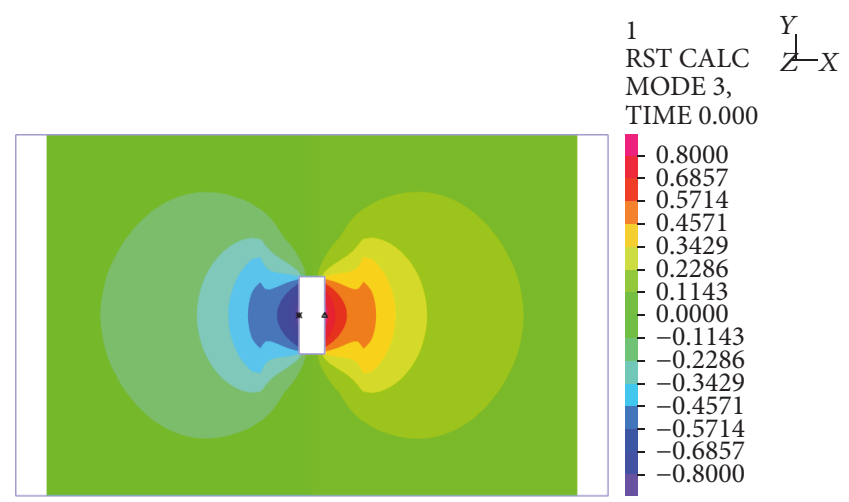

(d)
$Z$
$Y-X$

FIGURE 18: Nondimensional modal hydrodynamic pressures on the pier specimen without tip mass for the second mode along $x$-axis; profiles for a water level, $H_{\mathrm{w}}$, of $1.8 \mathrm{~m}$ along cutting planes: (a) $y=0 \mathrm{~m}$ and (b) $z=0.7 \mathrm{~m}$; profiles for a water level, $H_{\mathrm{w}}$, of $1.5 \mathrm{~m}$ along cutting planes: (c) $y=0 \mathrm{~m}$ and (d) $z=0.7 \mathrm{~m}$; profiles for a water level, $H_{\mathrm{w}}$, of $1.2 \mathrm{~m}$ along cutting planes: (e) $y=0 \mathrm{~m}$ and (f) $z=0.7 \mathrm{~m}$. 
in the distribution of the modal hydrodynamic pressures along the height of the specimen. In the second mode along $x$-axis, larger hydrodynamic pressures occur mainly around the pile cap and the lower half of the submerged pier body and the recorded pressure loads on the upper half of the pier body are smaller. The locations and magnitudes of the maximum hydrodynamic pressure remain almost unchanged for each water level considered. Again, these phenomena coincide well with the previous stated observation indicated by Figure 12(a).

The nondimensionalized hydrodynamic pressures for the first two modes along $y$-axis of the pier specimen without tip mass submerged by the selected three water levels, respectively, are depicted in Figures 19 and 20. The vertical cutting plane is taken to be $x=0 \mathrm{~m}$, passing through the middle of the pier specimen, and the horizontal cutting plane is taken to be $z=0.65 \mathrm{~m}$, passing through the location of the maximum hydrodynamic pressure. Figure 19 reveals that the modal hydrodynamic pressures are distributed evenly over the combined height of the pile cap and the pier body for the three considered water levels, and the maximum value of the recorded pressure keeps almost constant with the rising water level. Figure 20 tells that larger hydrodynamic pressures occur mainly around the pile cap and the lower part of the pier body in the second mode along $y$-axis. Similar to that of the first mode, the positions and values of the maximum hydrodynamic pressure in the second mode remain almost unchanged for the three considered water levels. These observations from Figures 19 and 20 are coincident with those obtained from Figure 12(b).

Figures 21 and 22 illustrate the influence of tip mass on the modal hydrodynamic pressures of the specimen. From Figure 21 it can be seen that, as the tip mass increases, higher hydrodynamic pressures develop in a narrower range along the pier height with a smaller pressure peak in the first mode, while in the second mode the overall profiles of the modal hydrodynamic pressures remain almost the same with slight difference being noted in the distribution range of higher hydrodynamic pressure along the pier height. Similar phenomena can be found from Figure 22. The observations in Figures 21 and 22 are consistent with the trends indicated in Figure 16.

From Figures 17, 19, and 21, it is shown that higher modal hydrodynamic pressures are mainly concentrated near the structure-water interfaces. The hydrodynamic pressures near the rigid-wall boundaries are practically zero, indicating that the length of the water tank along $x$-axis used for the tests was sufficient to ensure the accuracy of the modal test results along $x$-axis. Figures 18, 20, and 22 suggest that the width of the water tank along $y$-axis used in the tests was not large enough to simulate energy dissipation of propagating waves far from the pier specimen; nevertheless they also show that the hydrodynamic pressures near the rigid-wall boundaries are negligibly small when compared with those around the structure-water interfaces. These observations, combined with the results shown in Figure 10, can be used to support that the dimensions of the water tank selected for the tests were large enough and should not cause considerable deviations to the final test data. It is also important to note that the conclusions herein can only be applicable to the modal dynamic analysis and should not be directly extrapolated to seismic or other dynamic load response analyses of real bridges surrounded by water.

\section{Summary and Conclusions}

This paper presented an experimental program performed to investigate the effect of fluid-structure interaction on the modal dynamic response of water-surrounded slender bridge pier with pile foundation. A reduced scale slender bridge pier was designed and tested in various cases through forced vibration method. Four tip masses, that is, none, 12.1, 23.4, and $31.7 \mathrm{~kg}$, were considered in the tests to represent the effect of bridge superstructure mass. Sixteen water levels, varying from 0 to $1.8 \mathrm{~m}$, for an empty to full water tank, were defined in the tests. The vibration periods of the first four lateral modes, including the first two modes along $x$-axis and the first two modes along $y$-axis, were measured based on the water-pier system. Vibration period percentage increases of the four modes were determined as a function of water level and tip mass to assess the effect of fluid-structure interaction. Three-dimensional finite-element models were established for the tested water-pier system and analyzed under various combined cases of water level and tip mass. The numerical results were then validated against the recorded test data and a satisfactory agreement was achieved. Based on the validated models, the modal hydrodynamic pressures were calculated to find out the 3D distribution of hydrodynamic loads on the pier systems. Through this research the following conclusions can be drawn:

(1) the effect of fluid-structure interaction on the dynamic modal response of slender bridge pier increases as the water level rises, a phenomenon which becomes remarkable only when the pier body is submerged in water;

(2) compared with the fundamental vibration modes along $x$-axis and $y$-axis, respectively, higher order modes are influenced to a larger extent by fluidstructure interaction, especially those along $x$-axis;

(3) vibration period percentage increases of the modes along $x$-axis are significantly higher than those along $y$-axis, a result that can be attributed to the larger areas of fluid-structure potential interfaces perpendicular to $x$-axis than those perpendicular to $y$-axis;

(4) with the increase of water level, the period percentage increases of the second modes grow quickly in the beginning and then in a much slower pattern, whereas those of the first modes grows contrarily;

(5) the period percentage increases of the first modes along $x$-axis and $y$-axis, respectively, decrease with the increase of the tip mass, whereas those of the second modes show the opposite trend;

(6) larger hydrodynamic pressures are mainly concentrated around the upper half of the water-surrounded pier body for the first modes but are mainly distributed along the combined height of the pile cap and 


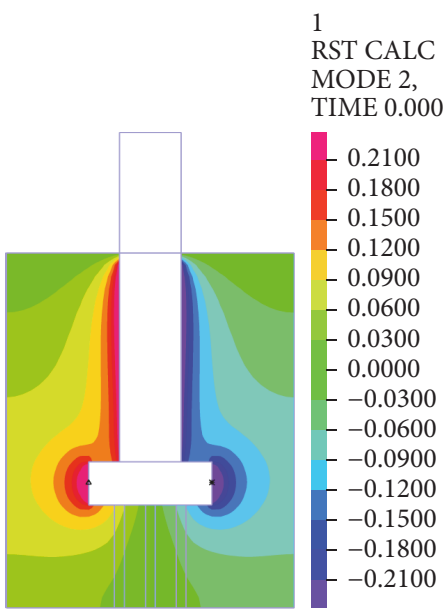

(a)

1 RST CALC MODE 2,

TIME 0.000

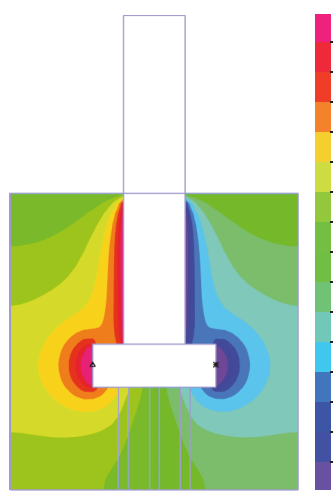

$-0.2100$

$-0.1800$

$-0.1500$

$-0.1200$

$-0.0900$

$-0.0600$

$-0.0300$

$-0.0000$

$--0.0300$

$-0.0600$

$-0.0900$

$-0.1200$

$-0.1500$

$-0.1800$

$-0.2100$

(c)

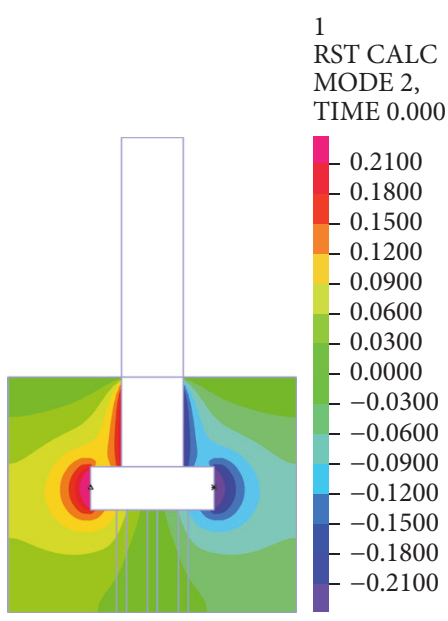

(e)

\section{$Z$
$\downarrow$
$-Y$ \\ $x$}

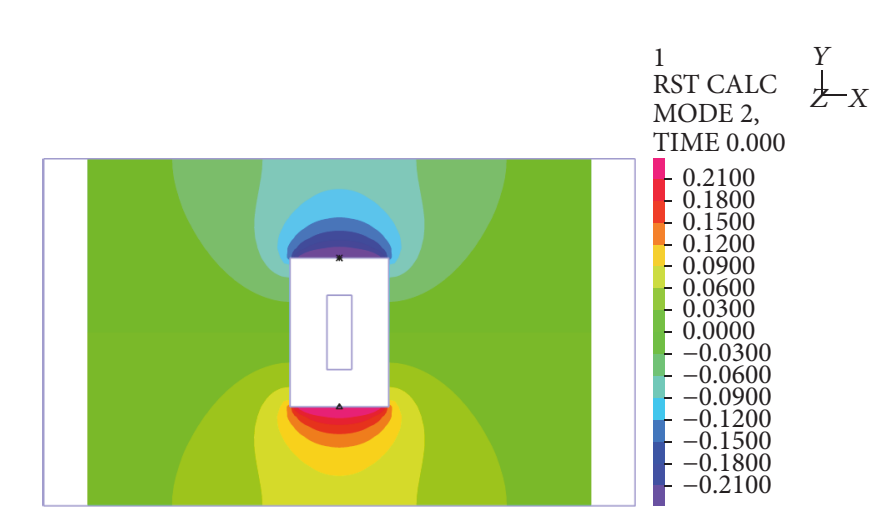

(b)

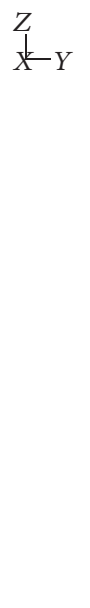

1

RST CALC

MODE 2,

TIME 0.000

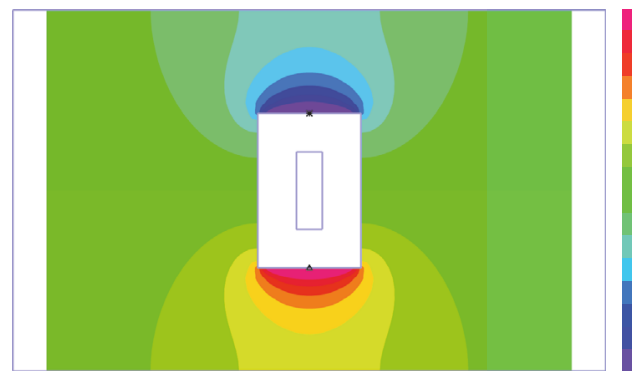

$-0.2100$

-0.1800
-0.1500
-

-0.1500
-0.1200

$-0.0900$

$-0.0600$

$-0.0300$

0.0000

-0.03000
$-\quad-0.0300$
$-\quad-0.0600$

-0.0600
--0.0900
-

$-0.1200$

$-0.1800$

(d)

\section{$Z$
$X-Y$} 00

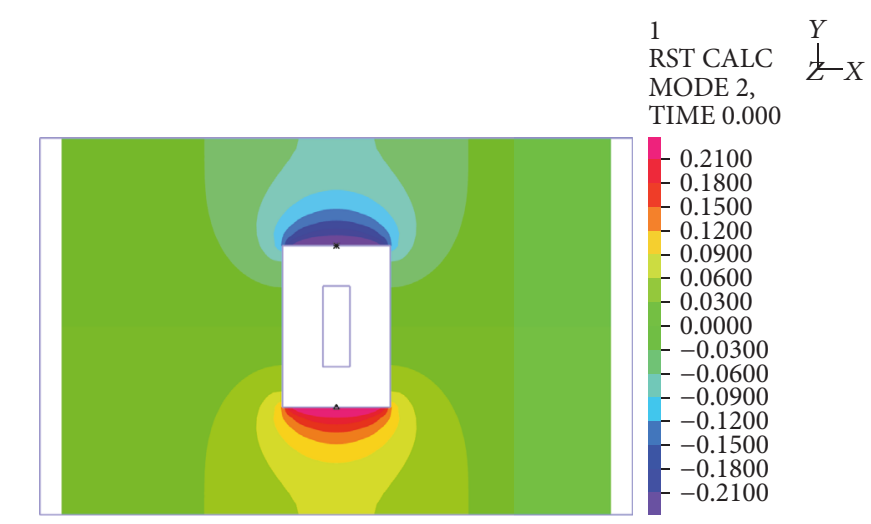

(f)

FIGURE 19: Nondimensional modal hydrodynamic pressures on the pier specimen without tip mass for the first mode along $y$-axis; profiles for a water level, $H_{\mathrm{w}}$, of $1.8 \mathrm{~m}$ along cutting planes: (a) $x=0 \mathrm{~m}$ and (b) $z=0.65 \mathrm{~m}$; profiles for a water level, $H_{\mathrm{w}}$, of $1.5 \mathrm{~m}$ along cutting planes: (c) $x=0 \mathrm{~m}$ and (d) $z=0.65 \mathrm{~m}$; profiles for a water level, $H_{\mathrm{w}}$, of $1.2 \mathrm{~m}$ along cutting planes: (e) $x=0 \mathrm{~m}$ and (f) $z=0.65 \mathrm{~m}$. 


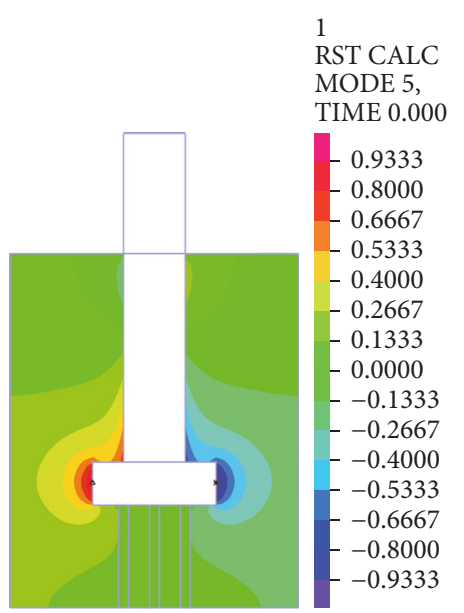

(a)

\section{$Z$
$X-Y$}

.

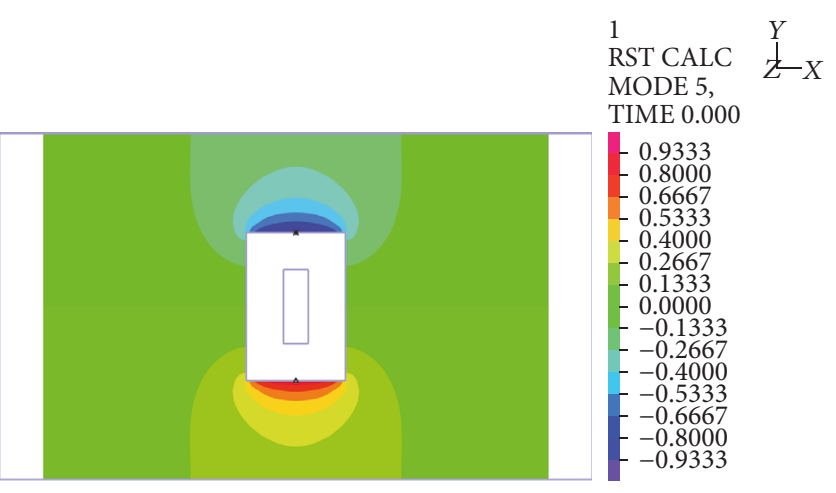

(b)

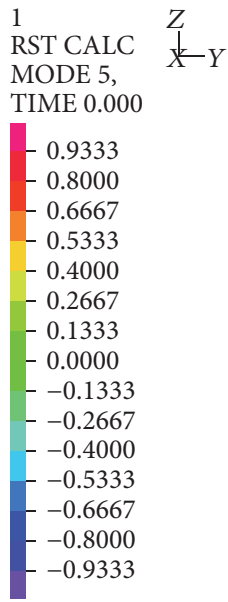

(c)

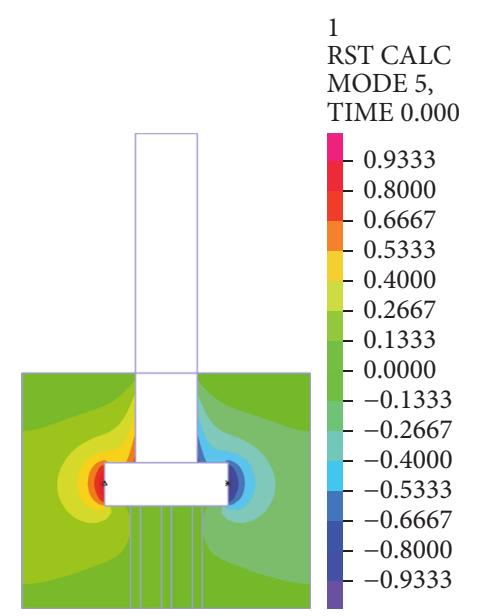

(e)

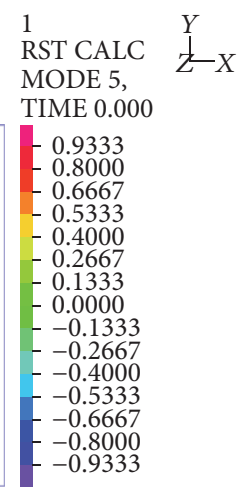

(d)

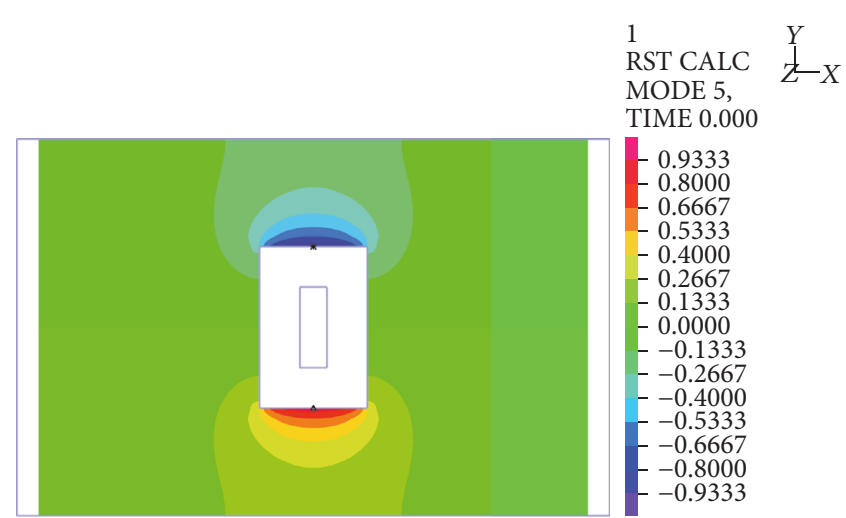

(f)

FIGURE 20: Nondimensional modal hydrodynamic pressures on the pier specimen without tip mass for the second mode vibration along $y$-axis; profiles for a water level, $H_{\mathrm{w}}$, of $1.8 \mathrm{~m}$ along cutting planes: (a) $x=0 \mathrm{~m}$ and (b) $z=0.65 \mathrm{~m}$; profiles for a water level, $H_{\mathrm{w}}$, of $1.5 \mathrm{~m}$ along cutting planes: (c) $x=0 \mathrm{~m}$ and (d) $z=0.65 \mathrm{~m}$; profiles for a water level, $H_{\mathrm{w}}$, of $1.2 \mathrm{~m}$ along cutting planes: (e) $x=0 \mathrm{~m}$ and (f) $z=0.65 \mathrm{~m}$. 


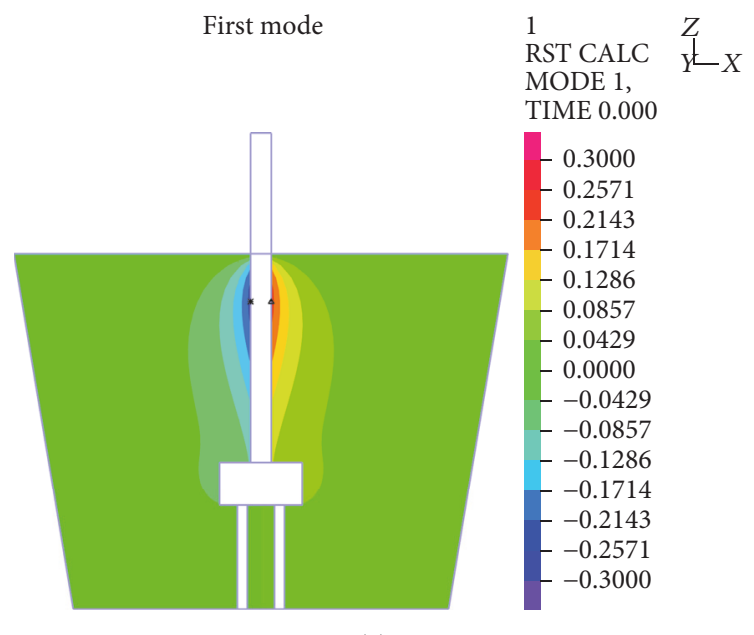

(a)

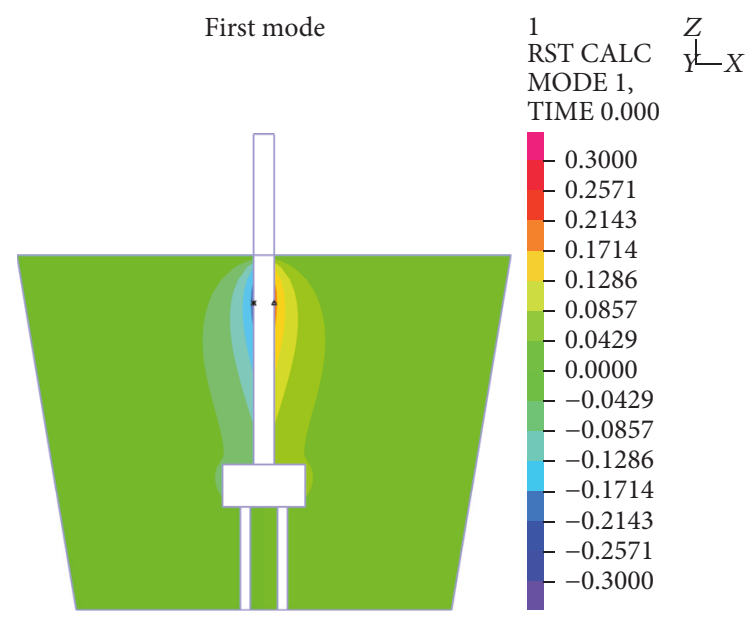

(c)

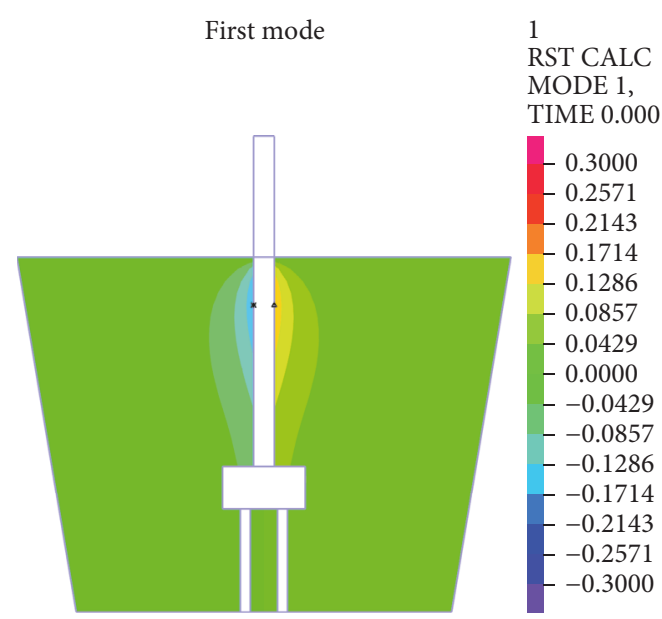

(e)

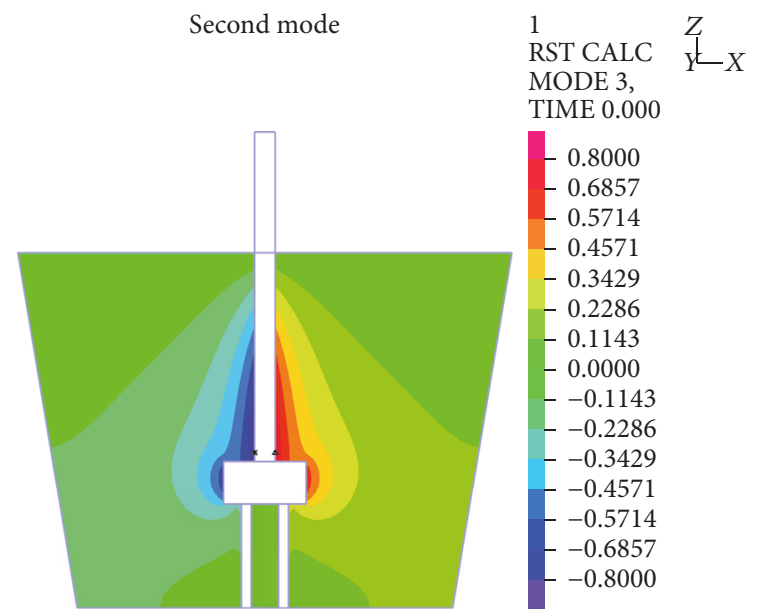

(b)

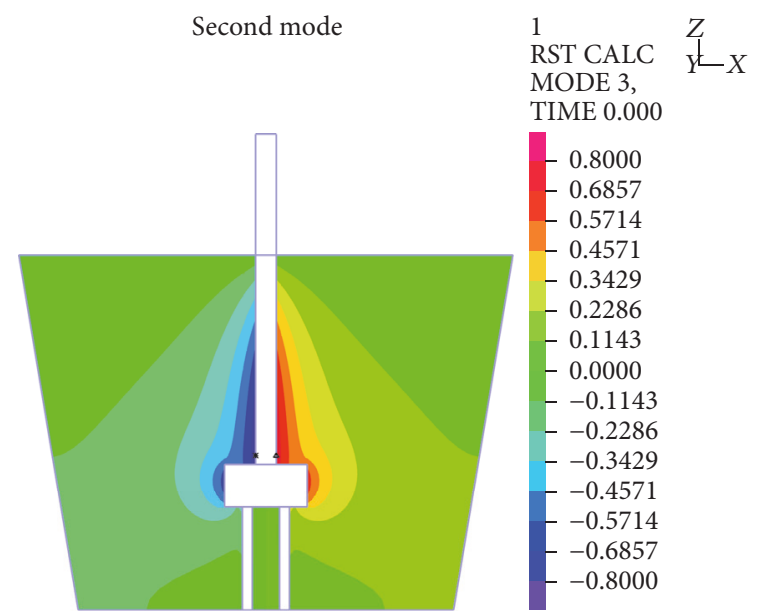

(d)

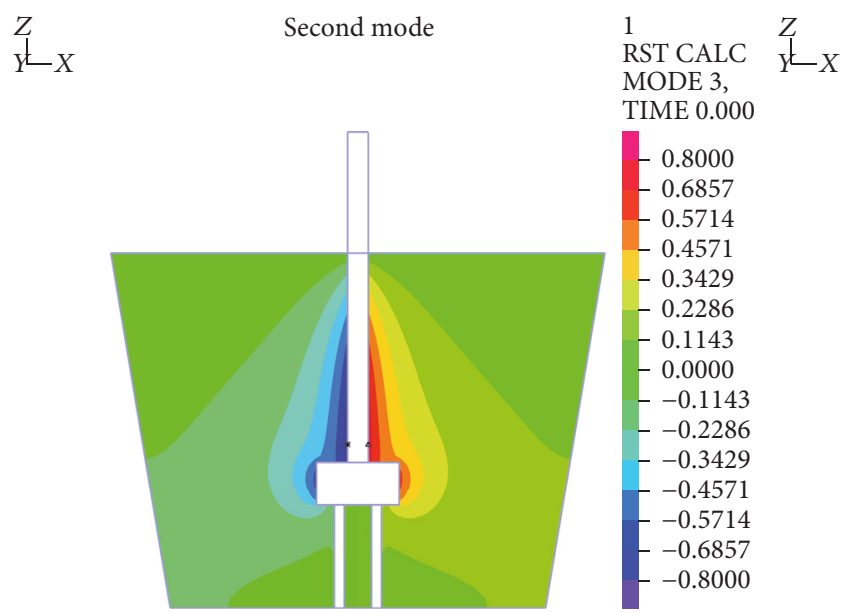

(f)

FIGURE 21: Nondimensional modal hydrodynamic pressures on the pier specimen in the first two modes along $x$-axis, with a water level, $H_{\mathrm{w}}$, of $1.8 \mathrm{~m}$, along $y=0 \mathrm{~m}$ cutting plane, corresponding to a tip mass of (a) and (b) $12.1 \mathrm{~kg}$; (c) and (d) $23.4 \mathrm{~kg}$; (e) and (f) $31.7 \mathrm{~kg}$. 


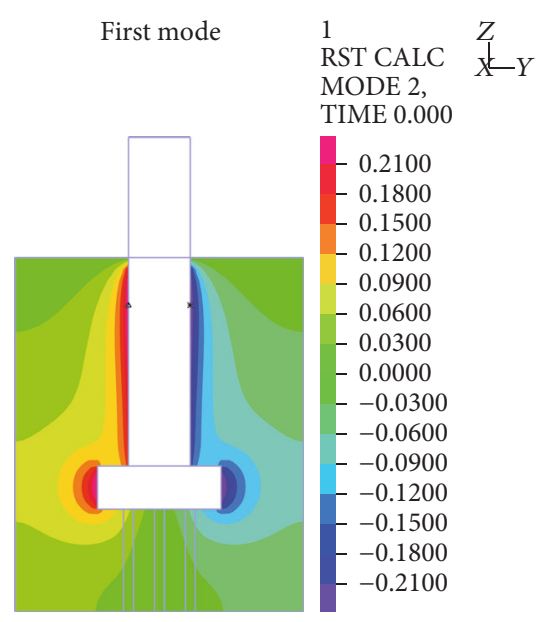

(a)

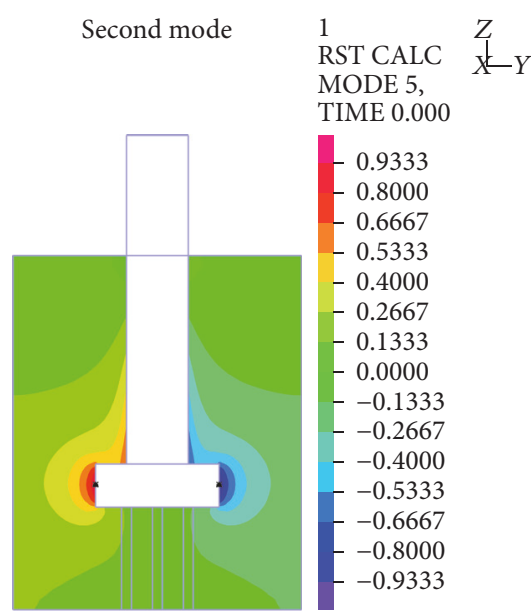

(d)

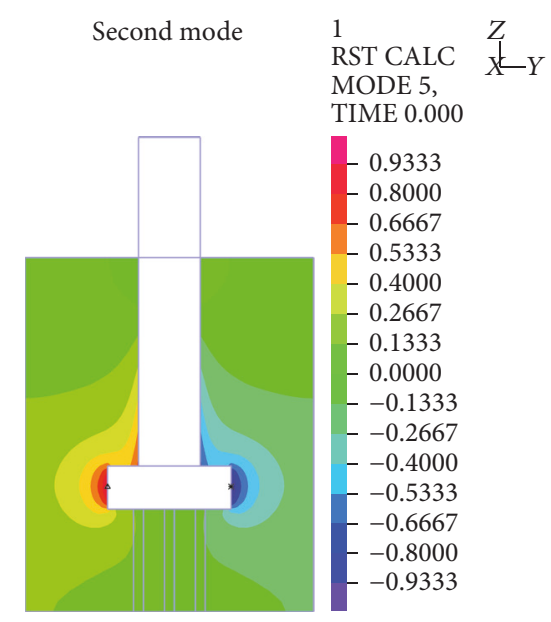

(b)

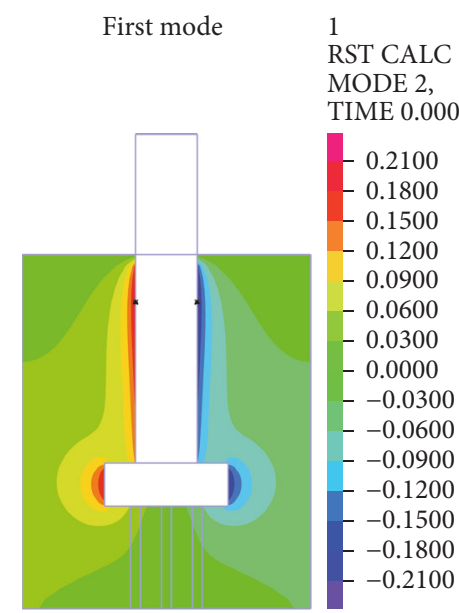

(e)

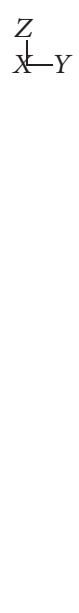

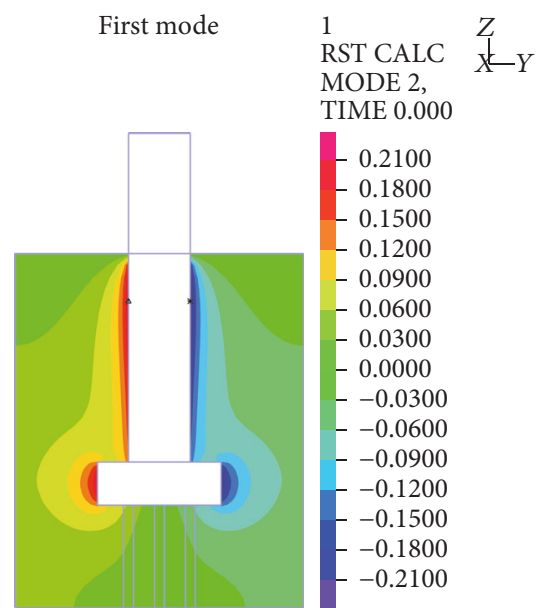

(c)

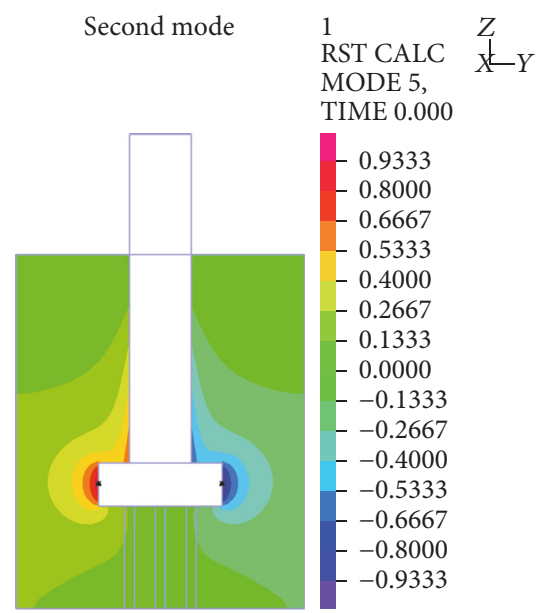

(f)

Figure 22: Nondimensional modal hydrodynamic pressures on the pier specimen in the first two modes along $y$-axis, with a water level, $H_{w}$, of $1.8 \mathrm{~m}$, along $y=0 \mathrm{~m}$ cutting plane, corresponding to a tip mass of (a) and (b) $12.1 \mathrm{~kg}$; (c) and (d) $23.4 \mathrm{~kg}$; (e) and (f) $31.7 \mathrm{~kg}$.

the lower part of the water-surrounded pier body for the second modes;

(7) as the tip mass increases, higher hydrodynamic pressures develop in a narrower range along the pier height with a smaller pressure peak in the first mode along $x$-axis, while the overall profiles of the modal hydrodynamic pressures almost remain the same with slight difference being noted in the distribution range of higher hydrodynamic pressure along the pier height.

\section{Disclosure}

Any opinions, findings, and conclusions expressed herein are those of the authors and do not necessarily reflect the views of the sponsors.

\section{Conflicts of Interest}

The authors declare that they have no conflicts of interest.

\section{Acknowledgments}

This work is supported by the National Nature Science Foundation of China (Grants nos. 51378406 and 51678459) and the Fundamental Research Funds for the Central Universities (Grants nos. 2016-YS-019 and 2017II24GX). The authors are very grateful for the supports.

\section{References}

[1] W. P. Yen, G. Chen, M. Yashinski et al., "Lessons in bridge damage learned from the Wenchuan earthquake," Earthquake Engineering and Engineering Vibration, vol. 8, no. 2, pp. 275285, 2009.

[2] W. H. P. Yen, G. D. Chen, M. Yashinsky et al., "China earthquake reconnaissance report: performance of transportation structures during the May 12, 2008, M7.9 Wenchuan earthquake," Tech. Rep. FHWA-HRT-11-029, Federal Highway Administration, Washington, DC, USA, 2011.

[3] R. B. Bittner, X. G. Zhang, and O. J. Jensen, "Design and construction of the Sutong Bridge foundations," in Proceedings of 
the DFI Specialty Seminar, pp. 1-18, Marine Foundations, Deep Foundations Institute, Hawthorne, NJ, USA, 2007.

[4] Q. Z. You, P. He, X. W. Dong, X. G. Zhang, and S. C. Wu, "Sutong bridge-the longest cable-stayed bridge in the world," Structural Engineering International, vol. 18, no. 4, pp. 390-395, 2008.

[5] S.-X. Liu, Y.-C. Li, and G.-W. Li, "Wave current forces on the pile group of base foundation for the east sea bridge, China," Journal of Hydrodynamics, vol. 19, no. 6, pp. 661-670, 2007.

[6] C.-Y. Liaw and A. K. Chopra, "Dynamics of towers surrounded by water," Earthquake Engineering \& Structural Dynamics, vol. 3, no. 1, pp. 33-49, 1974.

[7] A. Uściłowska and J. A. Kołodziej, "Free vibration of immersed column carrying a tip mass," Journal of Sound and Vibration, vol. 216, no. 1, pp. 147-157, 1998.

[8] H. R. Öz, "Natural frequencies of an immersed beam carrying a tip mass with rotatory inertia," Journal of Sound and Vibration, vol. 266, no. 5, pp. 1099-1108, 2003.

[9] C. H. Zhang, Numerical Modelling of Concrete Dam-Foundation Reservoir Systems, Tsinghua University Press, Beijing, China, 2001.

[10] J. Morison, M. O’Brien, J. Johnson et al., “The force exerted by surface waves on piles," Petroleum Transactions, vol. 189, pp. 149-154, 1950.

[11] C. Y. Liaw, "Earthquake response of axisymmetric tower structures surrounded by water," Tech. Rep. UCB/EERC-73/25, 1973.

[12] T. Sarpkaya, "Forces on cylinders and spheres in a sinusoidally oscillating fluid," Journal of Applied Mechanics, vol. 42, no. 1, pp. 32-37, 1975.

[13] K. Nagaya and Y. Hai, "Seismic response of underwater members of variable cross-section," Journal of Sound and Vibration, vol. 103, no. 1, pp. 119-138, 1985.

[14] C. C. Spyrakos and C. Xu, "Soil-structure-water interaction of intake-outlet towers allowed to uplift," Soil Dynamics and Earthquake Engineering, vol. 16, no. 2, pp. 151-159, 1997.

[15] J.-S. Wu and C.-T. Chen, "An exact solution for the natural frequencies and mode shapes of an immersed elastically restrained wedge beam carrying an eccentric tip mass with mass moment of inertia," Journal of Sound and Vibration, vol. 286, no. 3, pp. 549-568, 2005.

[16] W. L. Yang and Q. Li, "The expanded Morison equation considering inner and outer water hydrodynamic pressure of hollow piers," Ocean Engineering, vol. 69, pp. 79-87, 2013.

[17] A. N. Williams, "Earthquake response of submerged circular cylinder," Ocean Engineering, vol. 13, no. 6, pp. 569-585, 1986.

[18] A. Goyal and A. K. Chopra, "Earthquake analysis of intakeoutlet towers including tower-water-foundation-soil interaction," Earthquake Engineering \& Structural Dynamics, vol. 18, no. 3, pp. 325-344, 1989.

[19] J. T. Xing, W. G. Price, M. J. Pomfret, and L. H. Yam, "Natural vibration of a beam-water interaction system," Journal of Sound and Vibration, vol. 199, no. 3, pp. 491-512, 1997.

[20] G. C. Everstine, "A symmetric potential formulation for fluidstructure interaction," Journal of Sound and Vibration, vol. 79, no. 1, pp. 157-160, 1981.

[21] L. G. Olson and K.-J. Bathe, "An infinite element for analysis of transient fluid-structure interactions," Engineering Computations, vol. 2, no. 4, pp. 319-329, 1985.

[22] M. Di Pilato, F. Perotti, and P. Fogazzi, “3D dynamic response of submerged floating tunnels under seismic and hydrodynamic excitation," Engineering Structures, vol. 30, no. 1, pp. 268-281, 2008.
[23] N. Bouaanani and F. Y. Lu, "Assessment of potential-based fluid finite elements for seismic analysis of dam-reservoir systems," Computers and Structures, vol. 87, no. 3-4, pp. 206-224, 2009.

[24] K. Wei, W. Yuan, and N. Bouaanani, "Experimental and numerical assessment of the three-dimensional modal dynamic response of bridge pile foundations submerged in water," Journal of Bridge Engineering, vol. 18, no. 10, pp. 1032-1041, 2013.

[25] H. Goto and K. Toki, "Vibration characteristics and aseismic design of submerged bridge piers," in Proceedings of the $3 \mathrm{rd}$ World Conference on Earthquake Engineering, pp. 107-125, Auckland, New Zealand, 1965.

[26] N. G. Pegg, An experimental study of the seismic forces on submerged structures [dissertation, thesis], University of Britain Columbia, Vancouver, British Columbia, 1983.

[27] M. R. Maheri and R. T. Severn, "Experimental added-mass in modal vibration of cylindrical structures," Engineering Structures, vol. 14, no. 3, pp. 163-175, 1992.

[28] J.-S. Wu and M. Hsieh, "An experimental method for determining the frequency-dependent added mass and added mass moment of inertia for a floating body in heave and pitch motions," Ocean Engineering, vol. 28, no. 4, pp. 417-438, 2001.

[29] ADINA, "ADINA theory and modeling guide," Tech. Rep. ARD 13-8, 2013.

[30] W. Lai, J. J. Wang, X. Wei, and S. D. Hu, “The shaking table test for submerged bridge pier," Journal of Earthquake Engineering and Engineering Vibration, vol. 26, no. 6, pp. 164-171, 2006. 


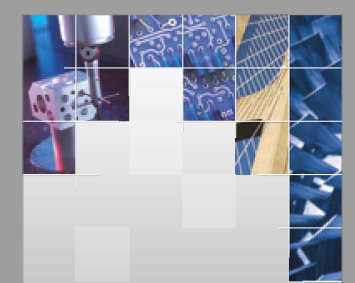

\section{Enfincering}
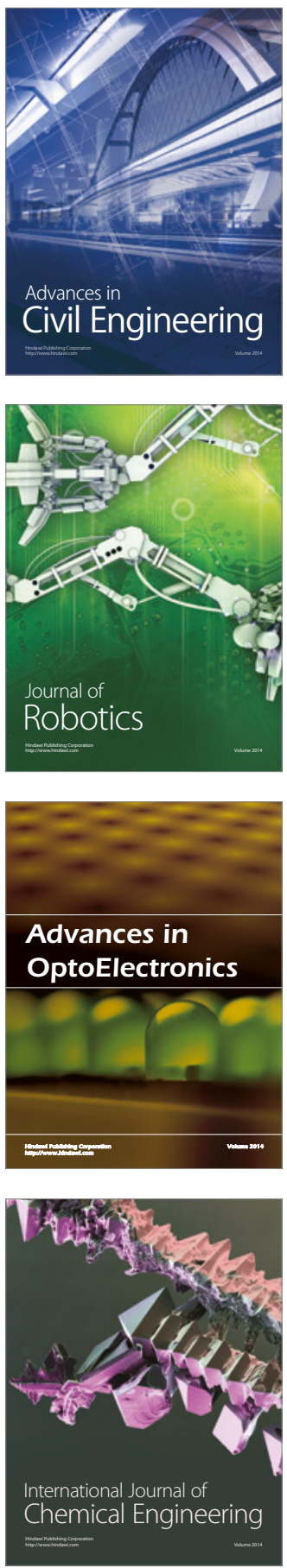

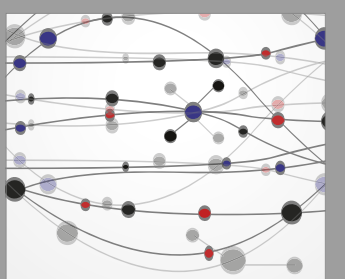

The Scientific World Journal

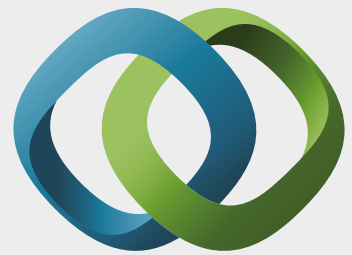

\section{Hindawi}

Submit your manuscripts at

https://www.hindawi.com
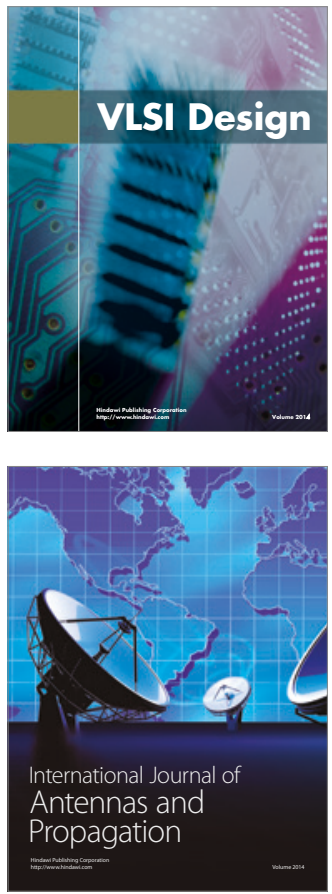

\section{Rotating}

Machinery
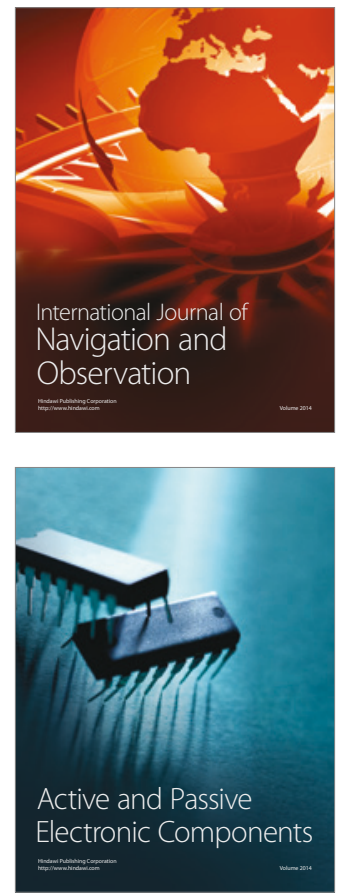
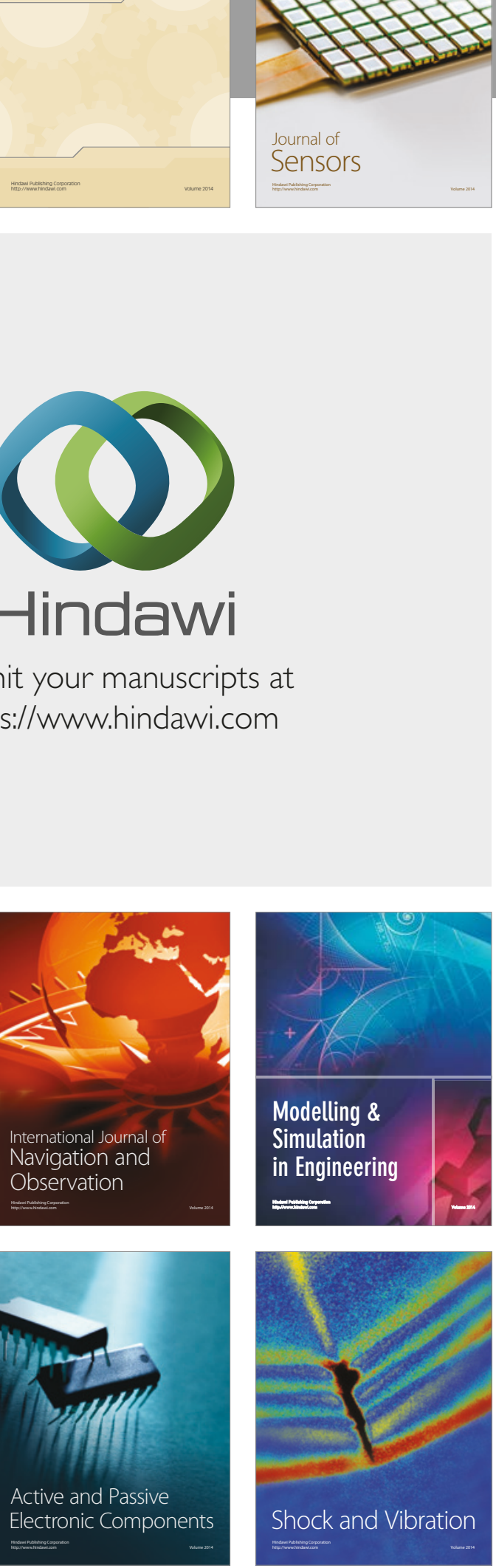
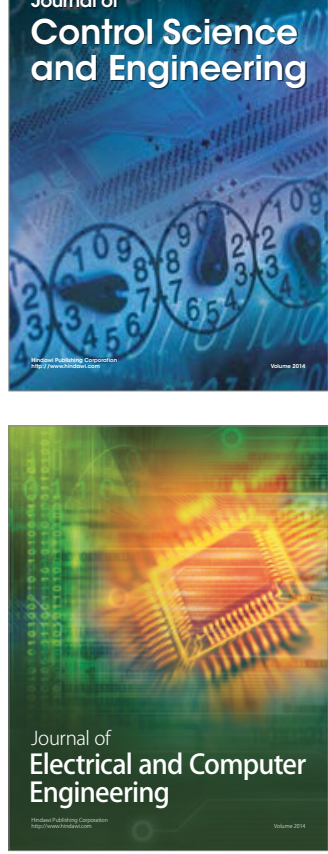

Distributed

Journal of

Control Science

and Engineering
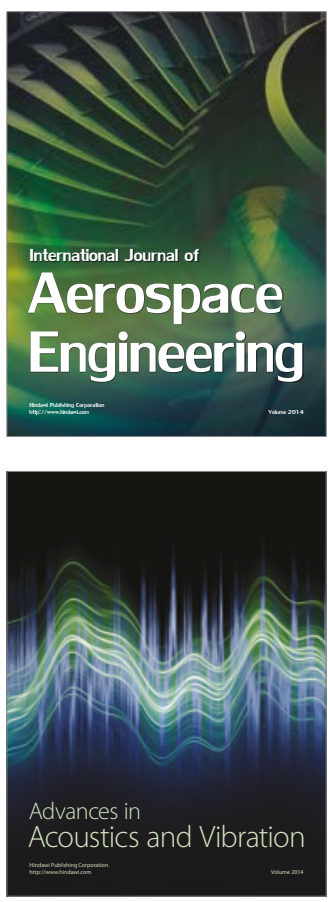

Sensor Networks 